\title{
A structural atlas of the developing zebrafish telencephalon based on spatially-restricted transgene expression
}

\author{
Authors \\ Katherine J. Turner ${ }^{1}$, Thomas A. Hawkins ${ }^{1}$, Pedro M. Henriques ${ }^{2}$, Leonardo E. Valdivia ${ }^{4,5}$, \\ Isaac H. Bianco ${ }^{2}$, Stephen W. Wilson ${ }^{1 *}$ and Mónica Folgueira ${ }^{1,3 *}$. \\ 1 Department of Cell and Developmental Biology, University College London, London, UK; \\ 2 Department of Neuroscience, Physiology \& Pharmacology, \\ University College London, London, UK; 3 Neurover Group, Centro de Investigacións \\ Cientificas Avanzadas (CICA) and Department of Biology, University of A Coruña, A \\ Coruña, Spain; ${ }^{4}$ Center for Integrative Biology, Facultad de Ciencias, Universidad Mayor, \\ Santiago, Chile. ${ }^{5}$ Escuela de Biotecnología, Facultad de Ciencias, Universidad Mayor, \\ Santiago, Chile.
}

*Corresponding authors.

\section{*Correspondence:}

Mónica Folgueira

m.folgueira@udc.es

Stephen Wilson

s.wilson@ucl.ac.uk

Keywords: telencephalon, eversion, zebrafish, atlas, egr3

\section{Abstract}

Zebrafish telencephalon acquires an everted morphology by a two-step process that occurs from 1 to 5 days post-fertilization (dpf). Little is known about how this process affects the positioning of discrete telencephalic cell populations, hindering our understanding of how eversion impacts telencephalic structural organisation. In this study, we characterise the neurochemistry, cycle state and morphology of an EGFP positive $(+)$ cell population in the 
telencephalon of $\operatorname{Et}(\text { gata2:EGFP })^{\text {bi105 }}$ transgenic fish during eversion and up to $20 \mathrm{dpf}$. We map the transgene insertion to the early-growth-response-gene-3 (egr3) locus and show that EGFP expression recapitulates endogenous egr3 expression throughout much of the pallial telencephalon. Using the gata2:EGFP bi105 transgene, in combination with other wellcharacterised transgenes and structural markers, we track the development of various cell populations in the zebrafish telencephalon as it undergoes the morphological changes underlying eversion. These datasets were registered to reference brains to form an atlas of telencephalic development at key stages of the eversion process (1dpf, $2 \mathrm{dpf}$ and $5 \mathrm{dpf}$ ) and compared to expression in adulthood. Finally, we registered gata2:EGFP ${ }^{\text {bi105 }}$ expression to the Zebrafish Brain Browser 6dpf reference brain (ZBB, see Marquart et al., 2015, 2017; Tabor et al. 2019), to allow comparison of this expression pattern with anatomical data already in ZBB.

\section{Introduction}

The telencephalon is the alar portion of the secondary prosencephalon (see Puelles and Rubenstein, 2003, 2015), consisting of the olfactory bulbs and the telencephalic lobes. It is responsible for higher brain functions, such as memory, emotions, cognition and higherlevel multisensory integration and motor control. In zebrafish, as in all other ray-finned fish, the telencephalon is everted, a markedly different morphology to that of other vertebrates that have an evaginated telencephalon (Wullimann and Mueller, 2004b; Folgueira et al., 2012).

The morphological differences between everted and evaginated telencephali complicate comparisons and establishing homologies. In ray-finned fish, the telencephalon consists of two solid lobes separated by a midline ventricle that also extends over the dorsal surface under the tela choroidea (Butler, 2000; Yamamoto et al., 2007; Braford, 2009; Mueller and Wullimann, 2009; Nieuwenhuys, 2009a; Folgueira et al., 2012, Porter and Mueller, 2020). In other vertebrates, the telencephalon is evaginated and consists of two hollow hemispheres that surround an inflated, lateral ventricle. There is consensus that the dorsal and ventral portions of the everted telencephalon are homologous to the pallium and subpallium respectively, but establishing further homologies has proven to be challenging, especially for the pallium (Wullimann and Mueller, 2004b; Northcutt, 2008, Nieuwenhuys, 2009a; Mueller et al., 2011; Ganz et al., 2012; Porter and Mueller, 2020). This is because eversion is more complex than just a simple lateral out-folding of the neural tube (Yoshimoto et al., 2007; Mueller et al., 2011; Folgueira et al., 2012; Porter and Mueller, 2020), as first proposed by Gage (1893) and Studnicka $(1894,1896)$. For instance, based on the analysis of 
early forebrain development, we showed that there are two early morphogenetic events critical to formation of an everted telencephalon in zebrafish (Folgueira et al., 2012). Our model showed that eversion is more complex than a simple out-folding of the neural tube, but its implications are yet to be determined by detailed analysis of the developmental changes in locations of discrete cell populations during eversion (Briscoe and Ragsdale, 2019). After the early developmental events that generate an everted telencephalon, other processes, such as cell differentiation and migration, will certainly contribute to generate the organization of pallial subdivisions observed in the adult (Yoshimoto et al., 2007; Mueller et al., 2011; Porter and Mueller, 2020).

The principle aim of this study was to better understand how the organisation of the telencephalon changes during early development, when key events of eversion happen. To achieve this, we characterised the $\operatorname{Et}\left(\right.$ gata2:EGFP) ${ }^{\text {bi105 }}$ transgenic line (Folgueira et al., 2012; Turner et al., 2016), mapped the insertion site to egr3 locus, examined egr3 gene expression, and characterised the neurochemistry, cell cycle state and cell morphology of labelled EGFP positive $(+)$ telencephalic cells. In combination with other well-characterized transgenic lines and structural markers, we tracked the distribution of various cell populations during early development. By combinatorial use of these diverse approaches we have generated a structural atlas of the developing zebrafish telencephalon, which should act as a framework, or scaffold to expedite further anatomical and functional studies.

\section{Materials and Methods}

\subsection{Fish Stocks and Maintenance}

Adult zebrafish (Danio rerio, Cyprinidae) were maintained under standard conditions that meet FELASA guidelines (Aleström et al., 2020): $28^{\circ} \mathrm{C}$ and $14 \mathrm{~h}$ light/10 h dark periods (Westerfield, 2000) at University College London (UCL) Fish Facility. Embryos were raised in fish water at $28^{\circ} \mathrm{C}$ and staged according to Kimmel et al. (1995). Phenylthiocarbamide (PTU, Sigma) at a concentration of $0.003 \% \mathrm{w} / \mathrm{v}$ was added to the fish water at $24 \mathrm{~h}$ post fertilization (hpf) to prevent pigment formation in larvae. All experimental procedures were conducted under licence from the UK Home Office, following UK Home Office regulations and/or European Community Guidelines on animal care and experimentation and were approved by animal care and use committees.

The following zebrafish strains were used in this study: AB and TL wild types, Et(gata2:EGFP) $)^{\text {bi105 }}$ (Folgueira et al., 2012), $\operatorname{Tg}\left(1.4 d l x 5 a-d l x 6 a\right.$ :GFP) ${ }^{\text {ot1 }}$ (Zerucha et al., 
2000), $\operatorname{Tg}\left(\right.$ isll:GFP) ${ }^{\mathrm{rw} 0}$ (Higashijima et al., 2000) and $\operatorname{Tg}(-10 \operatorname{lh} x 2 a: E G F P)^{\mathrm{zf} 176}$ (Miyasaka et al., 2009; 2014).

\subsection{BrdU Staining}

BrdU (5-bromo-2'-deoxyuridine) incorporation assay was performed on 4dpf larvae by first embedding fish in 1\% low-melting-point agarose and then injecting approximately $1 \mathrm{nl}$ of $10 \mathrm{mM}$ BrdU (Sigma) into the heart. Larvae were then removed from the agarose and allowed to freely swim for 2 hours at $28.5^{\circ} \mathrm{C}$. After anaesthesia and fixation, larvae were processed for immunohistochemistry (see below).

\subsection{Anaesthesia and fixation}

Specimens were deeply anesthetized in $0.2 \%$ tricaine methanesulfonate (MS222, Sigma) in fresh water and fixed in 4\% paraformaldehyde (PFA) in phosphate buffered saline (PBS) with 4\% sucrose by immersion. The tissue was then post-fixed in the same fixative for $24 \mathrm{~h}$ at room temperature. After this, cranial skin, jaw and other tissues were removed from embryos and larvae by fine dissection using two pairs of sharp forceps on embryos pinned in Sylgard (Turner et al., 2014). After washing in PBS and dehydration in methanol, they were kept at $-20^{\circ} \mathrm{C}$ for at least $24 \mathrm{~h}$. Brains from 20dpf fish and adults were dissected and kept in PBS at $4^{\circ} \mathrm{C}$ until use.

\subsection{Immunostaining}

Embryos and larvae were stained as whole mounts following standard procedures (Shanmugalingam et al., 2000; Turner et al., 2014). In brief, specimens were rehydrated to phosphate buffered saline with $0.5 \%$ Triton X-100 (PBS-T). After a brief proteinase digestion to improve permeability of the tissue, specimens were incubated with primary antibody overnight at $4^{\circ} \mathrm{C}$. Specimens were then washed in PBS-T and incubated with fluorescent secondary antibodies again overnight at $4^{\circ} \mathrm{C}$. After washing in PBS-T, embryos and larvae were mounted in $2 \%$ low-melting point agarose and imaged on a Leica confocal laser scanning system. For a detailed protocol on larval dissection, antibody labelling and mounting for imaging see Turner et al. (2014).

Brains from 20dpf fish were cryoprotected, frozen with liquid nitrogen-cooled methylbutane and cut in sections ( $12 \mu \mathrm{m}$ thick) on a cryostat. After mounting the sections on gelatinized slides, they were rinsed in PBS-T and preincubated with normal goat serum (Sigma, 1:10) for $1 \mathrm{~h}$. Next, they were incubated with a primary antibody overnight at room 
temperature and then with secondary fluorescent antibodies for $1 \mathrm{~h}$, followed by PBS washes. Sections then stained for 5 minutes in a solution of Sytox Orange diluted in PBS-T, then mounted using glycerol-based mounting medium and photographed under a conventional epifluorescence microscope (Nikon Eclipse 90i).

For staining brains from 20dpf fish as whole mounts we followed the same protocol as for larval whole mount immunostaining, but with longer proteinase digestion and primary antibody incubation (48 h).

Antibodies and dilutions used were as follows:

Primary antibodies: Rabbit anti-green fluorescent protein (GFP; Torrey Pines Biolabs, Cat\# TP401, dilution 1:1000), rat anti-GFP (Nacalai Tesque; Cat\# GF090R, dilution 1:1000), mouse anti-bromodeoxyuridine (BrdU, Roche; Cat\# B8434, dilution 1:300), mouse anti zona occludens 1 (ZO1, Invitrogen; Cat\# 33-9100, dilution 1:300), mouse anti-acetylated tubulin antibody (IgG2b; $\alpha$-tubulin; Sigma; Cat\# T7451, dilution 1:250), rabbit anti- $\gamma$ aminobutyric acid (GABA; Sigma; Cat\# A2052, dilution 1:1000), mouse anti-synaptic vesicle protein 2 (IgG1; SV2; DSHB; Cat\# AB 2315387, dilution 1:250), rabbit anti-DSRed antibody (Living Colours; Clontech; Cat\# 632496, dilution 1:300), rabbit anti- red fluorescent protein (RFP, MBL; Cat\#PM005; dilution 1:2000).

Secondary antibodies: Alexa Fluor 488 (Invitrogen, Goat anti-Rabbit, Cat\# A-11034, Goat anti-Rat Cat\# A-11006, Goat anti-Mouse, Cat\# A-11029, dilution all 1:200), Alexa Fluor 568 (Invitrogen, Goat anti-Mouse IgG, Cat\# A-11031, Goat anti-Mouse IgG2b, Cat\# A-21144, dilution all 1:200) and Alexa Fluor 633 (Invitrogen, Goat anti-Mouse IgG, Cat\# A21052; Goat anti-Mouse IgG1, Cat\# A-21126, dilution all 1:200). To detect anti-acetylated tubulin and anti-SV2 in the same sample, isotype-specific secondary antibodies were used: Alexa Fluor 568 (IgG2b) and Alexa Fluor 633 (IgG1).

\subsection{Whole mount fluorescent in situ hybridisation (FISH)}

The FISH protocol was adapted from Jülich et al. (2005) and performed as described in Turner et al. (2016). Digoxigenin probes were made by standard protocols and were detected using the anti-DIG POD antibody (Roche, 1:1000) and stained using Cy3-tyramide substrate (Perkin Elmer, 1:50 in amplification buffer). After staining, antibody labelling for GFP was performed as above using rabbit anti-green fluorescent protein (GFP, Torrey Pines Biolabs, 1:1000) and goat anti-rabbit Alexa Fluor 488 (Invitrogen, 1:200) antibodies without further PK digestion. Cell nuclei were labelled with TOTO3-iodide (Invitrogen, 1:5000). 
Embryos were mounted in $1 \%$ agarose in $80 \%$ glycerol/PBS solution and imaged on a Leica SP8 confocal microscope.

\subsection{Fluorescent Nucleic Acid Staining}

Larval brains were whole mount stained with Sytox Orange (S11368; ThermoFisher) and used for studying cell architecture and distribution of different nuclei. Following antibody labelling, larval brains were washed in PBS and then stained for 30 minutes in a solution of Sytox Orange diluted in PBS-T (1:20,000). Subsequently, brains were washed in PBS and mounted for imaging.

\subsection{Genome Walker mapping of enhancer trap insertion}

The genomic location of the insertion in the enhancer-trap line Et(gata2:EGFP) ${ }^{\text {bi105 }}$ was mapped using a linker-mediated approach with the Universal Genome Walker ${ }^{\mathrm{TM}} 2.0 \mathrm{Kit}$ (Clontech). A detailed user manual is available online. Since the $\operatorname{Et}(\text { gata2:EGFP })^{\text {bi105 }}$ line was made using the Tol2-transposase system for genomic insertion (Kawakami et al., 2000, 2004). Using this information, two nested primers specific to the tol2 sequence were designed: one for primary PCR (GSP1) and one for the secondary nested PCR (GSP2). These primers were non-overlapping, annealing to sequences as close to the end of the known sequence as possible. A combination of these primers (sequences below) and the ligated linkers/primer from the kit were used to generate four Genome Walker PCR amplicons from two restriction-generated genomic libraries. These amplicons were purified using Qiagen QIAquick PCR purification kit and checked for purity and concentration using a NanoDrop 2000C (ThermoScientific). Sanger-sequencing (Source BioScience, UK) using either stock primers such as M13F (within linker annealed kit constructs) or gene specific primers (see supplementary information for identified sequences) was checked for novel genomic sequence adjacent to the tol 2 sequence in each fragment, these sequences were aligned by BLAST/BLAT against the zebrafish genome. All four amplicons aligned to the same region of chromosome 8 (Fig. 1A). The insertion site was confirmed using PCR with primers specific to the specific EGFP employed in the transgenesis construct and the newly sequenced adjacent genomic sequence.

Nested sets of primers used with the adapter linked primers.

TTAAATTAAACTGGGCATCAGC, tol2_3 out_1

GGTTTGGTAATAGCAAGGGAAA, tol2_3 out_2 


\section{AAATACAAACAGTTCTAAAGCAGGA, tol2_5 out_1 \\ CCTTGTATGCATTTCATTTAATGTT, tol2_5 out_2}

\subsection{Genetic linkage analysis}

To confirm linkage between transgene and genome hits derived from Genome Walker use we employed traditional linkage mapping using simple sequence length polymorphisms (SSLPs)(Knapik et al., 1998). Briefly, nearby SSLPs were identified from zebrafish information network (ZFIN; zfin.org) webpages and Ensembl. A small panel of 48 transgenepositive, and 48 transgene-negative embryos were arrayed on a 96 well plate and genomic DNA was extracted by proteinase K digestion. PCRs for SSLPs were carried out on this arrayed DNA followed by gel electrophoresis. Where nearby SSLP markers were polymorphic between positive and negative groups, linkage was tested by measuring differential meiotic recombination between transgene positive and negative groups. The SSLP markers and primer sequences employed are listed below.

\begin{tabular}{|l|l|l|l|}
\hline $\begin{array}{l}\text { Marker } \\
\text { name }\end{array}$ & F primer & R primer & $\begin{array}{l}\text { Genbank } \\
\text { ref }\end{array}$ \\
\hline z9279 & TGCATAAAGTCAGGAGGTTCA & TCTGCGCTTAACAATGCACT & G40762 \\
\hline z21390 & CAAAAACACAGAACTGGGATTG & GTGGGAATTGGACTCAGGAA & G40246 \\
\hline z23039 & CCCTACTGTGAGCATGAGCA & GAACTGAGAGAATAGCAGGACGA & G39541 \\
\hline
\end{tabular}

\subsection{Preparation of sgRNAs, Cas9 mRNA.}

Template DNA for short guide RNAs (sgRNAs) synthesis was digested with DraI, and sgRNAs were transcribed using the MAXIscript T7 kit (Life Technologies). The pT3TSnCas9n plasmid (Addgene) (Jao et al., 2013) was linearized with XbaI (Promega) and mRNA synthesised with the mMessage mMachine T3 Transcription Kit (Ambion). Transcription reactions were incubated in a water bath at $37^{\circ} \mathrm{C}$ for $2 \mathrm{~h}$ or longer. To digest template DNA, 1 $\mu \mathrm{L}$ of TURBO DNase was added and reaction incubated for a further $15 \mathrm{~min}$ at $37^{\circ} \mathrm{C}$. The Cas9 mRNA was polyadenylated using the polyA tailing kit (Ambion). Cas9 mRNA and sgRNAs were purified using either the RNeasy Minikit (Qiagen) or Zymo columns.

\subsection{Microinjections}

Microinjection of DNA and RNA was performed using a borosilicate glass capillary needle attached to a Picospritzer III injector. Adult zebrafish were paired with dividers the 
night before injections. Dividers were removed the following morning and embryos were collected soon after to ensure they were at early 1 cell stage at time of injections. Embryos were aligned against a glass slide inside an upturned petri dish lid. The needle was calibrated to inject 1nl per embryo. Injections were performed into the cell for DNA and RNA.

\subsection{Single cell labelling using EGFP to Gal4 switching with CRISPR/Cas9.}

To achieve somatic switching of transgenes and mosaically label single or small groups of neurons within the $\operatorname{Et}(\text { gata2:EGFP) })^{\text {bi105 }}$ transgenic line we adapted a technique developed by Auer et al. (2014) using the modified donor plasmid hs:Gbait (Kimura et al., 2014). This CRISPR/Cas9-mediated knock-in of DNA cassettes into the zebrafish genome uses homology-independent double-strand break repair pathways. Co-injection of a donor plasmid with a sgRNA and Cas9 nuclease mRNA results in concurrent cleavage of the donor plasmid and the selected chromosomal integration site resulting in the targeted integration of donor DNA. Using an EGFP target sequence in the donor plasmid and a sgRNA against EGFP Auer et al (2014) effectively converted EGFP transgenic lines into Gal4 versions. Kimura et al (2014) modified the donor plasmid (hs:Gbait) to include a heat-shock promoter to increase the efficiency of the switching of EGFP to Gal4, as the Gal4 cassette would be expressed regardless of which orientation the hs:GBait integrates into the genome.

To achieve sparse labelling of single EGFP expressing neurons in Et(gata2:EGFP $)^{\text {bi105 }}$ injected embryos we added 5xUASTdTom DNA to the injection mixture. This led to very mosaic labelling with TdTom of neurons within the original EGFP expression pattern. All plasmids, including hs:GBait (Kimura et al., 2014), were a kind gift from Thomas Auer. For the acute substitution, each embryo was injected with a solution containing 60pg of sgRNA EGFP1, 150pg of Cas9 mRNA, 7pg of Gbait-hsp70:Gal4 and 5pg UAS:TdTom (Zhang et al., 2012). Embryos were screened for RFP expression from 24hpf onwards. Specimens with desired expression were fixed and processed for immunohistochemistry. Technical limitations of this labelling technique, due to genome editing occurring early in development, made it challenging to label later born neurons.

\subsection{Imaging}

Fish were mounted in $2 \%$ low melting point agarose, either in lateral or dorsal view, under a dissecting scope equipped with bright field and fluorescent filters. Imaging was performed using either Leica SP2 or SP8 Confocal Microscopes equipped with filter-free AOBS systems tuned to the appropriate GFP/RFP spectra, with either water 25x (NA: 0.95) 
or 40x (NA: 0.8) immersion lenses and 3x line averaging. Imaging parameters varied for different data sets and scale references are included on figures to account for these differences. Due to the opacity of the tissue, imaging beyond a total depth of $200-300 \mu \mathrm{m}$ from the surface of the fish brain was not possible.

\subsection{Image analysis and Editing}

Confocal stacks were processed using Fiji (ImageJ) and/or Volocity and/or Imaris. Images and figures were assembled using Adobe Photoshop or Adobe Illustrator.

Unless otherwise stated, the nomenclature used in this study is largely based on that of the adult zebrafish brain atlas (Wullimann et al., 1996) and early zebrafish brain development (Mueller and Wullimann, 2005). For larval optic tectum nomenclature, we followed Robles et al. (2011).

\subsection{Image registration}

Registration of image volumes was performed using the ANTs toolbox version 2.1.0 (Avants et al., 2011) using UCL's computer cluster, typically with a Dell C6220 node with 16 cores and $16 \mathrm{~GB}$ of RAM. Individual brain volumes for each age and orientation (lateral or dorsal view) were registered using as template either the ZO1, acetylated tubulin, or both imaging channels of an example fish in each category. All registrations were manually assessed for global and local alignment accuracy.

As an example, to register the 3D image volume in fish1-01.nii to the reference brain ref.nii, the following parameters were used:

antsRegistration -d 3 -float 1 -o [fish1_, fish1_Warped.nii.gz] -n BSpline -r [ref.nii, fish101.nii,1] -t Rigid[0.1] -m GC[ref.nii, fish1-01.nii,1,32, Regular,0.25] -c [200x200x200x0,1e8,10] -f 12x8x4x2 -s 4x3x2x1-t Affine[0.1] -m GC[ref.nii, fish1-01.nii,1,32, Regular,0.25] c [200x200x200x0,1e-8,10] -f 12x8x4x2 -s 4x3x2x1-t SyN[0.1,6,0] -m CC[ref.nii, fish101.nii,1,2] -c [200x200x200x200x10,1e-7,10] -f 12x8x4x2x1-s 4x3x2x1x0

The deformation matrices computed above were then applied to any other image channel $\mathrm{N}$ of fish1 using:

antsApplyTransforms -d 3 -v 0 -float - n BSpline - i fish1-0N.nii -r ref.nii -o fish10N_Warped.nii.gz -t fish1_1Warp.nii.gz -t fish1_0GenericAffine.mat 
A registered 6dpf $\operatorname{Et}(\text { gata2:EGFP) })^{\text {bi105 }}$ stack (.PNG file accompanying this article, see supplementary data) can be viewed in the online Zebrafish Brain Browser browser (Marquart et al., 2015; Marquart et al., 2017) at http://metagrid2.sv.vt.edu/ chris526/zbb/. To add any ZBB registered stack, go to "Lines" and select "Custom". From there you can "Select File" to select the .PNG file. Click "Load" and the stack should now display in the browser, which you can then visualise with any other ZBB registered line or label.

\subsection{Terminology}

According to the neuromeric model (Puelles and Rubenstein, 2003, 2015), the neuraxis is bent so the optic chiasm is the anterior tip of the brain. Based on this model, the alar telencephalon would be divided in an anterior subpallium and a posterior pallium (see Herget et al., 2014). The telencephalon, however, has been classically divided in a dorsal division or pallium and a ventral division or subpallium. Thus, for clarity in our anatomical descriptions, we use body axis coordinates ("rostral"-towards the nose; "caudal"- towards the tail; "dorsal" and "ventral") for brain structures (Fig. 2, top schematic) (see also Herget et al., 2014 and Porter and Mueller, 2020). We use the terms "alar" and "basal" whenever appropriate (Herget et al., 2014; Porter and Mueller, 2020) (Fig. 2, top schematic).

\section{Results}

\subsection{The Et(gata2:EGFP) $)^{\text {bi105 }}$ transgene neighbours early growth response 3 (egr3) and} EGFP expression closely matches endogenous egr3 expression.

EGFP is expressed in the telencephalon of $\operatorname{Et}(\text { gata2:EGFP })^{\text {bi105 }}$ larvae and is a useful marker to understand telencephalic morphogenesis (Folgueira et al., 2012; Turner et al., 2016). The genomic location of this transgene was, however, not known.

To identify this locus, we mapped the position of the $\operatorname{Et}(\text { gata2:EGFP })^{\text {bi105 }}$ insertion using linker-mediated PCR, confirmed by genetic linkage mapping. Our results showed that the genomic insertion of the transgene in $\operatorname{Et}(\text { gata2:EGFP })^{\text {bi105 }}$ fish lies 6,543bp upstream of the first exon of Early Growth Response 3 (egr3) (see methods and Fig. 1A-B) which encodes a transcription factor that functions as an immediate-early growth response gene in some systems (Yamagata et al., 1994).

With the insertion point established, we then assessed whether Et(gata2:EGFP) $)^{\text {bi105 }}$ transgene expression recapitulates egr 3 expression. We examined egr 3 mRNA expression using fluorescent in-situ hybridisation in combination with immunohistochemistry for EGFP 
in Et(gata2:EGFP) $)^{\text {bi105 }}$ embryos. There was extensive co-localisation of EGFP protein and egr3 mRNA in the telencephalon from 48hpf (Fig. 1C-D'). At this stage, there is also strong egr3 mRNA expression in the midline of the optic tectum, but little EGFP protein observed in this location (Fig. 1C-C", D-D'). By 6dpf, egr3 mRNA expression overlaps with EGFP protein in the pallium, subpallium and optic tectum of Et(gata2:EGFP) $)^{\text {bi105 }}$ embryos (Fig. 1EF'").

In summary, this demonstrates that the $\operatorname{Et}(\text { gata2:EGFP })^{\text {bi105 }}$ transgene insertion maps near egr3, and EGFP expression is nested within the endogenous egr3 expression.

\subsection{Changes in telencephalic topography between $18 \mathrm{hpf}$ and $20 \mathrm{dpf}$}

We used wholemount immunohistochemistry against EGFP in Et(gata2:EGFP $)^{\text {bi105 }}$ fish from $18 \mathrm{hpf}$ to $20 \mathrm{dpf}$ to follow the development of pallial and subpallial telencephalic populations, combined with anti-acetylated tubulin to highlight the progressive development of major axon pathways (Fig. 2A-F'; Wilson et al. 1990; Chitnis and Kuwada 1990). Following EGFP expression over time does not allow us to definitively identify the same cells at each stage, but our observations strongly support there being stable transgene expression within the same discrete telencephalic cell populations over time.

By 20hpf, the first few EGFP+ cells were evident ventrally in the telencephalon (not shown), dorsal to the anterior commissure and forebrain bundle (telencephalic tract of Chitnis and Kuwada, 1990; supraoptic tract of Wilson et al., 1990). By 24 hpf, EGFP+ cells are divided in two populations (Fig. 2A): "population A" is located just rostral to the anterior commissure (subpallial nucleus, see below) and "population B" is located more caudally and dorsally (pallial population, see below). At this stage, EGFP+ axons and growth cones from these neurons were observed within the forebrain bundle (Fig. 2A).

By 36hpf, an increase in EGFP+ cells was evident in both populations (Fig. 2B), especially in "population B" (pallial population). The cells of "population A" (subpallial population) extended processes to the dorsal part of the anterior commissure (Fig. 2B-C), where they intermingled with processes from the EGFP+ cells of "population B". Some fibres extended along the forebrain bundle towards caudal forebrain areas (Fig. 2B inset).

To confirm the regional identity of the EGFP+ telencephalic cells, Et(gata2:EGFP) ${ }^{\text {bi105 }}$ embryos were labelled with immunohistochemisty against EGFP and fluorescent in situ hybridisation against $d l x l a$ and $t b r l$ at 36 hpf (MacDonald et al., 2010) (Fig. 3). tbrl encodes a transcription factor that marks developing glutamatergic cells (Hevner et al., 2001, 2006; Puelles et al., 2000; Englund et al., 2005). In zebrafish, tbr1 is 
mainly expressed in the pallium, with two smaller additional expression sites in the septal areas and in telencephalic populations that derive from the prethalamic eminence (Mione et al., 2001; Wullimann and Mueller., 2004a,b; Mueller et al., 2008, Turner et al., 2016). dlx1a is expressed in proliferative and immature neurons of the subpallium and preoptic area (MacDonald et al., 2010; Wullimann and Mueller, 2004a, b). Using these markers we found that for "population B", EGFP+ cells were nested within the $t b r 1+$ domain (Fig 3A-A" and E-E'') and were predominantly $d l x l a$ negative (-) (Fig. 3B-B' and F-F'). These observations confirmed the pallial character of this population. The transgene does not label the full set of pallial cells, as there are cells that are $t b r l+$ but EGFP-, including the ventricular zone (Fig. 3A-A" and E-E'). Single confocal slices through 36hpf larvae showed the EGFP+ cells of "population A" at the border of $t b r 1+$ domain (Fig. 3C-C", and G-G'), but they are nested within the subpallial marker $d l x l a$ (Fig. 3D-D" and H-H'). The location of "population A" in relationship to $t b r l$ and $d l x l a$ domains confirms its subpallial identity.

From $36 \mathrm{hpf}$ to $3 \mathrm{dpf}$ (Fig. 2B-C) the number of EGFP+ cell bodies again increased in the pallial EGFP+ population. By 3dpf, a few EGFP+ fibres (but no cell bodies) were observed in the inner layer of the olfactory bulb. From $3 \mathrm{dpf}$ to $5 \mathrm{dpf}$, the number of EGFP+ pallial cell bodies in the telencephalon increased substantially, as did the overall size of the pallial territory (Fig. 2C-D).

From $5 \mathrm{dpf}$ to $20 \mathrm{dpf}$, we observed a dramatic increase in the size of the telencephalic pallial lobes relative to other neighbouring areas (Fig. 2E-F), such as the olfactory bulb and habenula. Although the EGFP+ subpallial cells were initially positioned rostral to the EGFP+ pallial cells, by 20dpf they sit ventral to this cell population (Fig. 2E- F). Large numbers of EGFP+ fibres were observed coursing towards caudal areas via the forebrain bundle (Fig. 2F) and crossing the midline in the anterior commissure (Fig. 2F). Fibres originating from the subpallial population were also observed in the anterior commissure at this stage (Fig. 2E-F).

The changes in the relative positions and sizes of the subpallial and pallial EGFP+ populations over time (from $24 \mathrm{hpf}$ to $20 \mathrm{dpf}$ ) reflect the morphological changes that occur as a result of eversion (24hpf to $5 \mathrm{dpf}$ ) and telencephalic growth (5dpf to $20 \mathrm{dpf}$ ) (Folgueira et al., 2012; Dirian et al., 2014; Furlan et al., 2017)

As the anatomical divisions between regions are clearer by $20 \mathrm{dpf}$, we could more precisely determine the identity of the different EGFP+ populations at this stage. Rostrally, many EGFP+ fibers (but no cell bodies) were present in the internal cell layer of the olfactory bulbs (Fig. 4A-B). In the telencephalic lobes, we observed that EGFP expression was not consistently strong throughout the dorsal telencephalon/pallium (Fig. 4B-E). Following 
nomenclature of Castro et al. (2006; see also Yañez et al., 2021), the principal areas of EGFP expression in the pallium were the medial zone (Dma and Dm of Castro et al., 2006), lateral zone (Dl) (Fig. 4B-E), central zone (Dc) (Fig. 4C-D) and scattered cells in the dorsal zone (Dd) (fig. 4C-E). In contrast to 4dpf larval expression (apparently in the whole pallium, excluding pallial derived olfactory bulb cells), we found very few EGFP+ cells in the anterior region of the lateral zone (Dla) and in the posterior zone (Dp) (Fig. 4B, E). EGFP expression was also excluded from the pallial ventricular zone (Fig. 4B-E). This suggests that EGFP expression is excluded from radial glia and proliferative cells which occupy these areas. A few EGFP+ cells were found in the lateral subpallium and close to the lateral forebrain bundle (lfb) (Fig. 4C, inset i). Based on this location, these subpallial cells could be part of the lateral nucleus of the ventral telencephalon (Vl; see Mueller et al., 2008; Mueller and Guo, 2009; Ganz et al., 2012).

\subsection{Et(gata2:EGFP ${ }^{\text {bil05 }}$ ) drives EGFP expression in post-mitotic glutamatergic telencephalic neurons}

The position of EGFP+ cells distant from the ventricular zone (Fig. 5A-C), suggested that they are post-mitotic neurons. To ascertain if this is correct, we treated Et(gata2:EGFP) $)^{\text {bi105 }}$ larvae with short pulses of $\mathrm{BrdU}$ at $4 \mathrm{dpf}$ and then performed immunostaining against EGFP and BrdU. The gata2:EGFP+ cells did not incorporate BrdU and, consequently, they are most probably non-proliferative, post-mitotic neurons (Fig. 5DD'),

To further characterise the EGFP+ cells, we assessed if they are glutamatergic and/or GABAergic. Co-immunostaining against GFP and GABA showed no co-expression in the pallium at 4dpf (Fig. 5E). GABAergic cell bodies were intermingled with the EGFP+ cell bodies in a salt and pepper manner (Fig. 5iii-iv). Some EGFP+ cells in the subpallium were GABAergic (arrowheads in Fig. 5H). GABAergic neurons in the pallium are likely migrated interneurons (Wullimann and Mueller, 2004b; Mueller et al., 2006) and our results confirm that EGFP is not expressed in GABAergic pallial interneurons.

To test whether the EGFP+ cells are glutamatergic, a cocktail of probes against vglut2a/slc17a6b and vglut2b/slc17a6a (see Higashijima et al., 2004) was used for fluorescent in situ hybridisation on $4 \mathrm{dpf} \operatorname{Et}(\text { gata2:EGFP) })^{\text {bi105 }}$ embryos. This probe mix labels neurons in the forebrain very broadly, but areas of strong GABAergic expression, such as the subpallium, preoptic region and prethalamic areas lack staining. EGFP protein in the telencephalic neuropil (arrows) surrounding GFP+ cells (arrowheads) co-localises with vglut2 
mRNA (Fig. 5G-H). No or very faint vglut 2 mRNA expression was noted in subpallial cells (not shown).

In summary, these results show that EGFP+ telencephalic cells are post-mitotic, and based on cell morphology and location, are most likely to be differentiated neurons. The EGFP+ pallial population contain glutamatergic neurons, while the subpallial EGFP+ cluster contains GABAergic neurons.

\subsection{Individual morphologies of EGFP+ neurons in Et(gata2:EGFP) ${ }^{b i 105}$ larvae.}

The density of pallial EGFP expression in Et(gata2:EGFP) $)^{\text {bi105 }}$ larvae prevents any analysis of the morphology and projections of individual neurons. To visualise sparsely labelled neurons, we employed the CRISPR/Cas9 approach developed by Auer et al. (2014) and further modified by Kimura et al. (2014) to excise the EGFP transgene and mosaically insert Gal4. We modified this method slightly by adding a UAS:TdTomato construct to the injection mix. The mosaic inheritance of this DNA construct, layered upon the already mosaic conversion to Gal4, together with fine process staining properties of TdTomato, permitted both increased mosaicism and better labelling of neuronal processes (Schematic Fig. 6)

Injection of the CRISPR/Cas9/EGFP guideRNA/Ga14/UAS cocktail into one cell stage $\operatorname{Et}(\text { gata2:EGFP) })^{\text {bi105 }}$ embryos lead to mosaic RFP labelling of small numbers of pallial neurons (Fig. 6A-I). All observations of morphology were made at $6 \mathrm{dpf}$, when the eversion process is almost complete. Labelled pallial neurons fell into two obviously distinct morphologies:

1. A population of neurons surrounding a central core of telencephalic neuropil (demarcated by SV2 expression, Fig. 6B). These cells had monopolar morphology with their single process extending towards the neuropil core before ramifying into multiple dendrites that formed a dense tangle with dendrites of adjacent neurons. Some labelled processes were also present in the contralateral telencephalic neuropil core (Fig. 6B). We were unable to ascertain whether these contralateral processes originated from these monopolar pallial neurons, perhaps crossing the anterior commissure, or other subpallial cells labelled in this specimen. Some processes also projected to caudal regions through the forebrain bundle. A survey of the single neuron morphologies registered to the mapzebrain atlas (Kunst et al., 2019) with soma located in the pallium $(n=28)$ revealed some pallial neurons projecting through the forebrain bundle to innervate caudal regions, 
such as the hypothalamus. None of the pallial neurons in this mapzebrain dataset had processes that crossed in the anterior commissure to elaborate processes in the contralateral pallium. So, although this cannot be definitively ruled out, it seems more likely such processes originate from subpallial gata2:EGFP+ neurons.

2. A population of multipolar neurons with stellate morphology (Fig. 6G-I). These neurons were positioned either at the dorsal surface or within the central neuropil core. These cells extended multiple processes directly from the cell body that appeared to encase small areas of neuropil or groups of cell bodies (Fig. 6G-I).

These experiments also allowed us to analyse the morphology of subpallial cells (Fig. $6 \mathrm{~J}-\mathrm{Q})$. Figure $6 \mathrm{~K}$ and $\mathrm{L}$ shows one such neuron whose cell body lay just rostral to the anterior commissure. This neuron was monopolar, with an elaborate dendritic arbour, some with spines, in the vicinity of the anterior commissure (Fig. 6K-L). The cell extended a bifurcated axon bilaterally down the left and right forebrain bundles to reach downstream targets that may include the ventral entopeduncular nucleus (vENT, arrow Fig. 6K), preglomerular, tuberal and hypothalamic areas (Fig. 6K). While the dendrites of this cell ramified only ipsilaterally, axon collaterals were bilateral and overtly symmetrical. Another example of a subpallial projection neuron with predominantly ipsilateral projections (Fig 6M-N) innervated similar caudal regions. Processes from this neuron also crossed the midline in the anterior commissure to terminate in the vicinity of the contralateral ventral entopeduncular nucleus. Axonal processes also crossed the midline in the hypothalamus. The subpallial neurons shown in Fig. 6J-J", with cell bodies located at the midline, showed similar innervation of commissural regions and long descending axons. We observed one cell within the anterior commissure (Fig. 6O-Q). This cell exhibited cocoon-like dendrites, tightly coiling within the ac itself. It sent one process rostrally into the contralateral pallium at the border with the olfactory bulb and another caudally through the lateral forebrain bundle to the posterior tuberculum (PT).

A survey of single neuron morphologies registered to mapzebrain atlas (Kunst et al., 2019) with somata located in the subpallium $(n=139)$ showed long-projecting neurons comparable to those shown in $6 \mathrm{~K}-\mathrm{M}$ to be very common with around $70 \%$ projecting either bilaterally or ipsilaterally to caudal regions, predominantly the hypothalamus, interpeduncular nucleus, posterior tuberculum and raphe nuclei. Unlike pallial cells in 
mapzebrain, the subpallial neurons frequently innervate the contralateral subpallium and pallium via the anterior commissure.

Mosaic analysis of neuron morphologies in $\operatorname{Et}\left(\right.$ gata2:EGFP) ${ }^{\text {bi105 }}$ larvae demonstrated that, even at larval stages, telencephalic cells already have elaborated intricate processes and dendritic arbors.

\subsection{Registration of transgene expression reveals the morphogenetic rearrangements of telencephalic regions during development.}

As we have described, the $\operatorname{Et}(\text { gata2:EGFP) })^{\text {bi105 }}$ transgene labels post-mitotic pallial cells, as well as a small group of subpallial cells. The restricted pallial expression of EGFP makes it a useful tool to track telencephalic cell populations through key stages of telencephalic development, particularly relating to eversion.

To build on our previous analyses of pallial eversion in zebrafish (Folgueira et al., 2012), we have taken advantage of non-linear volumetric image registration to register brains with labelling of different cell populations/structures to reference brains (Figures 7 and 8; Marquart et al., 2015, 2017; Randlett et al., 2015). We used acetylated tubulin labelling, common between all datasets, as a reference channel (Fig. 7E, K, Q; not shown in 8). These registered datasets describe how major telencephalic cell populations/structures (olfactory bulb, pallium, subpallium, and tela choroidea) change position relative to each other during development.

\section{Olfactory Bulb}

To view changes in olfactory bulb position and cell populations during early telencephalon development, the following transgenes were used in combination with the Et(gata2:EGFP) ${ }^{\text {bi105 }}$ transgene in registered data sets:

1. $\operatorname{Tg}(-10 \operatorname{lh} x 2 a: E G F P)^{\mathrm{zf} 176}$ (Fig. 7D, J, P, V; Fig. 8D, J, P, V) labels a subset of mitral cells, the principle output neurons of the olfactory bulb (Miyasaka et al., 2009, 2014)

2. $\operatorname{Tg}(1.4 d l x 5 a-d l x 6 a: G F P)^{\text {otl }}$ (Fig. 7B, H, N, T; Fig. 8B, H, N, T) labels a subset of olfactory bulb GABAergic interneurons ( $\mathrm{Li}$ et al., 2005). Figure 9 shows $\operatorname{Tg}(1.4 d l x 5 a-d l x 6 a: G F P)^{\text {ot1 }}$ in comparison with $\operatorname{Et}(\text { gata2:EGFP })^{\text {bi105 }}$ in frontal view. 
3. Anti-acetylated tubulin immunohistochemistry labels olfactory bulb glomeruli, amongst other structures (Fig. 7 E, K, Q; Fig. 9D, Fi; see Folgueira et al., 2012).

The first mitral cells to differentiate by $1 \mathrm{dpf}$ (Figs. 7D, F, 8D, E) were located within the dorsal telencephalon, close to the anterior intra-telencephalic sulcus (AIS). By this stage, mitral cells had already extended processes (Fig. 7D). Between 2dpf (Figs. 7J, 8H) and 5dpf, the telencephalic domain caudal to the olfactory bulb expanded greatly, increasing the distance between the OB and the AIS (Figs. 7P, R, 8P, Q). Mitral cell axons reached the pallium and right habenula via the olfactory tracts and stria medullaris respectively (Fig. 7J, P, 8P-Q; see also Miyasaka et al., 2009, 2014). Olfactory bulb interneurons, visualised with the 1.4dlx5a-dlx6a:GFP transgene, could be differentiated based on cell morphology. By $2 \mathrm{dpf}$, these interneurons already extended processes towards the olfactory glomeruli (not shown), which increase in morphological complexity from 2 dpf to $5 \mathrm{dpf}$ (Figs. 7N, 8N, 9Fi).

\section{Pallium}

The development of the pallium, as visualised through the changes in expression of gata2:EGFP in Et(gata2:EGFP) ${ }^{\text {bi105 }}$ fish (Figs. 7A, G, M, S; 8A, G, M, S), has already been well covered in earlier parts of this paper. Here we compared EGFP expression with that in $\operatorname{Tg}(1.4 d l x 5 a-d l x 6 a: G F P)^{\text {ot1 }}$ fish, in which pallial GABAergic interneurons of subpallial origin are labelled (Mione et al, 2008; Yu et al., 2011), and in $\operatorname{Tg}(-10 \operatorname{lh} x 2 a: E G F P)^{\mathrm{zf} 176}$ fish. We observed that 1.4dlx 5a-dlx6a:GFP+ interneurons had a salt and pepper distribution in the pallium (Figs. 7N, 8N), being more sparse in number than gata2:EGFP+ cells (Figs. 7M, 8M, Q, 9Fi-vi). Note that registration of $\operatorname{Tg}(1.4 d l x 5 a-d l x 6 a: G F P)^{o t l}$ data in lateral view (4dpf) in combination with the other markers was not satisfactory (hence not shown), but this was not the case for the dorsal view (Fig. 8Q) The morphological complexity of $1.4 \mathrm{dlx} 5 \mathrm{a}-$ dlx6a:GFP+ pallial interneurons increased over time, such that by $4 / 5 \mathrm{dpf}$ they ramified dense processes throughout the pallial neuropil (Figs. 7N, 8N, Q, 9Fiii-iv). The -10lhx2a:EGFP zf176 transgene labels a neuropil within the pallium, within which axons from olfactory mitral cells terminate. This neuropil, which is nested within the gata2:EGFP+ pallial domain, may give rise to the posterior zone of the dorsal telencephalic area (labelled Dp in Fig S1 D-E; see Miyasaka et al., 2099;2014)

\section{Subpallium}


To observe how eversion affects subpallial populations, two transgenic lines were imaged in combination with the $\operatorname{Et}\left(\right.$ gata2:EGFP) ${ }^{\text {bi105 }}$ line.

1. $\operatorname{Tg}(1.4 d l x 5 a-d l x 6 a: G F P)^{\text {otl }}$ (Fig. 7B, H, N, T; 8B, H, N, T; 9D-F) labels neuronal precursors and GABAergic neurons in regions of the subpallium and preoptic region (MacDonald et al., 2010; Yu et al., 2011). Based on the expression pattern of $d l x 5 a$ mRNA in the adult, this transgene is likely to label the dorsal (Vd), ventral $(\mathrm{Vv})$, supracomissural $(\mathrm{Vs})$, central $(\mathrm{Vc})$, lateral $(\mathrm{Vl})$ and posterior divisions of subpallium (Vp) (see Ganz et al., 2011). These divisions are not well differentiated by $5 \mathrm{dpf}$, so we were unable to confirm this expression pattern.

2. $\operatorname{Tg}\left(\right.$ isll:GFP) ${ }^{\mathrm{rw} 0}$ (Fig. 7C, I, O, U \& Fig. 8 C, I, O, U) (see Higashijima et al., 2000) shows a more restricted expression in the subpallium than the 1.4dlx5adlx6a:GFP ${ }^{\text {ot } 1}$ transgene. Recently, GFP expression in the adult brain has been extensively described in this transgenic line (see Baeuml et al., 2019) where the transgene labels neurons in the ventral subpallium $(\mathrm{Vv})$, ventral part of the dorsal subpallium (Vdv) and ventral domain of the supracommisural subpallium (Vs)] (see Baeuml et al., 2019; Porter and Mueller, 2020). The transgene is also expressed in the preoptic region (see Baeuml et al., 2019).

At 1dpf, the ventral gata2:EGFP+ cluster overlapped with the 1.4dlx5a-dlx6a:GFP+ domain (Figs. 7A-B, F; 8A-B, E; 9A-B, Cii, D-E, Fii), but not with the isl1:GFP+ one (Figs. 7C, F; 8C, E-F; see also S1). Pallial gata2:EGFP+ cells were located dorso-laterally to the 1.4dlx5a-dlx6a:GFP+ domain at this stage (Fig. 8A-B, E). At 2dpf, 1.4dlx5a-dlx6a:GFP expression was largely complementary to gata2:GFP expression (Figs. 7G, H, L, 8G, H, K, L), marking the pallial- subpallial boundary (Fig. 8K). At this stage, viewing from a dorsal aspect (Fig. 8K) showed that the gata2:EGFP+ (pallium) and 1.4dlx5a-dlx6a:GFP+ regions are distributed radially, with gata2:EGFP+ pallial cells located dorsolateral to the $1.4 \mathrm{dl} \times 5 \mathrm{a}-$ dlx6a:GFP+ domain. This arrangement changes with elongation of the telencephalon along its rostro-caudal axis from $2 \mathrm{dpf}$ to $5 \mathrm{dpf}$ (Fig. $8 \mathrm{M}-\mathrm{Q}, \mathrm{R}-\mathrm{W}$ ).

\section{Expansion of the tela choroidea}

The tela choroidea is a thin sheet of neuroepithelial origin that encloses the dorsal part of telencephalic ventricle of the everted telencephalon. At 1dpf, the telencephalic ventricle, delineated by anti-ZO1 labelling (this antibody labels apical cell junction proteins in both the tela choroidea and the cells lining the ventricle, see Fig. S2), is restricted 
medially, becoming larger caudally at the level of the AIS (Fig. 8A-D, F). At this stage, both 10lhx2a:EGFP+ mitral cells (Fig. 8D, F) and gata2:EGFP+ pallial cells (Fig. 8A, F) were not covered by the ventricular surface and the tela choroidea dorsally, thus the telencephalon was not yet everted. By $2 \mathrm{dpf}$, the number of gata2:EGFP+ and 1.4dlx5a-dlx6a:GFP positive cells increased, with the caudalmost telencephalic parenchyma expanding into the AIS (Fig. 8G-H, K-L). Thus, a portion of the pallium becomes covered by the ventricular surface and associated tela choroidea, so from this stage the telencephalon (pallium) can be described as everted (Fig. 8G, L). By 5dpf most pallial cells are covered by the tela choroidea with the exception of very few gata2:EGFP+ pallial cells located rostrolaterally (Fig. 8M, 8R). This shows that the pallium is not completely everted by $5 \mathrm{dpf}$ (Fig. $8 \mathrm{M}, \mathrm{R}$ ), but it will be at later stages. Thus, it seems that eversion process does continue after $5 \mathrm{dpf}$, at least at extreme rostral locations. The olfactory bulb was clearly not everted, as the rostral attachment of the tela choroidea or taenia (for full details on the taeniae and eversion see Nieuwenhuys, 2009b) was just caudal to the olfactory bulb (Fig. 8P, V).

In addition to registering these transgenes at key stages during telencephalic eversion, we also imaged the Et(gata2:EGFP) ${ }^{\text {bi105 }}$ transgenic line at 6dpf, the stage of development used in the Zebrafish Brain Browser atlas (ZBB). Figure S1 shows a snapshot of the registered Et(gata2:EGFP) $)^{\text {bi105 }}$ expression pattern as viewed in the online $\mathrm{ZBB}$ viewer. A .PNG file is available for download (see supplementary data) so that users may upload this expression pattern and compare/combine it with any other labels registered to ZBB.

\section{6. gata2: EGFP expression in $4 \mathrm{dpf}$ and $20 \mathrm{dpf}$ larval stages}

Although the focus for this study has been the telencephalon, gata2:EGFP is expressed at other sites in the developing and mature CNS that will be described here for 4dpf and 20dpf larval zebrafish.

\section{4dpf zebrafish.}

To characterise gata2:EGFP $P^{\text {bi105 }}$ expression, we used anti-GFP immunocytochemistry combined with anti-SV2 counterstaining to highlight anatomical landmarks (Turner et al., 2014). In the secondary prosencephalon, outside the telencephalon, we found EGFP expression in the lateral hypothalamus (Fig. 10 A,B). In the diencephalon, we observed a few neurons in the left-sided parapineal organ (Turner et al., 2016 and Fig. 9C), superficial pretectum, lateral and medial areas of the posterior tuberculum. In the midbrain, scattered EGFP + cell bodies in the periventricular gray zone of the optic tectum extended dendrites 
into the superficial tectal neuropil (Fig. 10A,C). Based on location and morphology, these EGFP+ neurons could represent periventricular interneurons [Robles et al., 2011; type XIV cells of Meek and Schellart (1978)/ small periventricular cells of Vanegas et al. (1974)]. In the hindbrain, several EGFP+ cell bodies were present in the superior raphe, areas of the reticular formation (Fig. 10B-B') and caudally in areas of the medulla oblongata (Fig. 10CC''). In all regions, expression appeared to be predominantly in neurons rather than ventricular cells/glia.

Despite the EGFP being a cytoplasmic variant, transgene expression (detected by immunohistochemistry) labelled several tracts and neuropil domains (Fig. 10B). The superficial tectal neuropil was EGFP+ (Fig. 10A-A', C-C'"); most of these fibres appeared to originate from cell bodies located in the periventricular gray zone, however some could have other origins. The horizontal commissure in the hypothalamus also contained EGFP+ fibres (Fig. 10B-B')' Finally, at caudal rhombencephalic levels, EGFP+ fibres were present in the medial (MLF) and lateral (LLF) longitudinal fascicles.

\section{$\underline{20 d p f \text { zebrafish }}$}

EGFP expression was more scattered at 20dpf (Fig. 4) than 4dpf (Fig. 8), but expression areas were consistent with those at $4 \mathrm{dpf}$. At $20 \mathrm{dpf}$, there was more mosaicism in expression within and between individuals, suggesting transgene silencing over time. This mosaicism was even more prevalent in adult transgenic fish (not shown). The only regions with de novo expression observed were in the cerebellum and vagal lobe (Fig. 4K).

In the basal secondary prosencephalon, we observed EGFP+ cells in the inferior hypothalamic lobes (Fig. 4G-J). In the alar diencephalon, we observed that the parapineal (ppn) was labelled, as previously described in Turner et al. (2016) at $1 \mathrm{mpf}$ (Fig. 4F and inset ii). EGFP+ fibers from the left-sided parapineal innervate the left dorsal habenula. At the same level as the habenulae, a small group of EGFP+ pretectal cells were present just above the forebrain bundle (Fig. 4F). In the basal diencephalon, EGFP+ cells were found in the preglomerular complex, torus lateralis, scattered cells in anterior and posterior tuberal regions (Fig. 4G-J).

In the midbrain and hindbrain there were only a few areas of expression. Transverse sections at the level of the optic tectum showed EGFP+ cell bodies in the PGZ and in the stratum album central of the optic tectum (Fig. 4G-I) that extended processes, most probably dendrites, dorsally into the stratum fibrosum griseum superficially and stratum opticum, consistent with $4 \mathrm{dpf}$ (see above). Also consistent with 4dpf, in the hindbrain, we observed 
EGFP+ neurons in the superior and intermediate reticular formation (Fig. 4J and inset iii) and superior raphe (Fig. 4K). In addition, we observed faintly EGFP+ cells in the valvula and corpus cerebelli (Fig. 4K and inset iv), likely to represent eurydendroid and/or Purkinje cells, and EGFP+ cells in the vagal lobe (Fig. 4L). These last two populations are additional to those observed in the 4dpf larva.

In summary, our analyses show EGFP expression in Et(gata2:EGFP) ${ }^{\text {bi105 }}$ transgenic fish is restricted to specific areas in the brain that are broadly consistent between 4dpf and $20 \mathrm{dpf}$.

\section{Discussion}

In this study, we have performed a detailed analysis of spatially restricted transgene expression in the telencephalon, in combination with other markers, to follow eversion and regionalisation of the zebrafish telencephalon during larval development. The registration of data from transgenic lines and other structural markers onto reference telencephali at key timepoints during development provides a framework atlas of major regions, structures and cell populations within the developing telencephalon. These datasets are available for further refinement through addition of further datasets and incorporation within other atlases, such as the Zebrafish Brain Browser (Marquart et al., 2015, 2017) within which we have registered a 6dpf Et(gata2:EGFP) $)^{\text {bi105 }}$ dataset (Supp fig. S1).

\subsection{An atlas of telencephalon development}

To understand how neural circuits control behaviour it is necessary to integrate wellannotated structural data with functional data (Arrenberg and Driever, 2013). This is challenging with respect to the teleost telencephalon that exhibits an everted morphology, rendering direct comparison with other vertebrate telencephali difficult. The repertoire of tools available for dissecting the anatomy and function of neural circuits has increased dramatically in the last few years (Scott, 2009; Leung et al., 2013; Feierstein et al., 2015; Föster et al., 2017, 2018; Robles et al., 2017), and includes the creation and characterisation of many transgenic lines expressing fluorescent proteins in discrete brain areas (Kwan et al., 2007; Scott et al., 2007; Takeuchi et al., 2015; Kawakami et al., 2010; Suster et al., 2011; Randlett et al., 2015; Marquart et al., 2017). Despite this wealth of tools and resources, there is still need of well-annotated baseline structural data that can be used to annotate reference brains (Ronnenberger et al., 2012; Marquart et al., 2015, 2017; Randlett et al., 2015). 
Existing neuroanatomical resources for zebrafish include 3D atlases based on confocal data during development and in the adult (Bryson-Richardson et al., 2007; Ullmann et al., 2010; Ronnenberger et al., 2012; Marquart et al., 2015, 2017; Randlett et al., 2015; Kunst et al., 2019; Kenney et al., 2021; zebrafishbrain.org). However, these atlases are usually based on a single developmental timepoint, so cannot communicate the gross morphological changes happening early in development. Here we present an atlas of the zebrafish telencephalon during key stages of development (1dpf, 2dpf and 5dpf). Our 5dpf annotations are easily extended to 6dpf, the stages presented in the Zebrafish Brain Browser (Marquart et al., 2015, 2017), Zebrafish Brain Atlas (Randlett et al., 2015) and mapzebrain (Kunst et al., 2019).

We have used anti-acetylated tubulin as an anatomical reference instead of cytoplasmic/nuclear staining often used in other atlases (Ronnenberger et al., 2012; Marquart et al., 2015; Radlet et al., 2015). We observed that, as previously shown in VibeZ (Ronnenberger et al., 2012), this labelling works well as a reference channel and has the added bonus that one can view the development of the axonal scaffold through development. We also include the marker ZO1, which delineates the extension of the ventricular zone and allows the degree of eversion to be tracked. Given there are portions of the ventricle that, as a result of eversion, are difficult to visualize without markers (Nieuwenhuys, 2009b), ZO1 or other ventricular zone markers are crucial when building a reference telencephalon resource.

\subsection{Eversion and "outside-in" construction mode of the teleost telencephalon.}

Eversion models have failed so far to explain how morphogenetic events during development lead to the organization of the pallial regions in the adult (Yamamoto et al., 2007; Mueller et al., 2011; Porter and Mueller, 2020). After the primary events of eversion from 1dpf to $5 \mathrm{dpf}$ (Folgueira et al., 2012), there is a subsequent major expansion of the telencephalon that affects its organization (present results; Dirian et al., 2014; Furlan et al., 2017). With the main events of eversion occurring so early (mostly by 1-5dpf) and growth so late, this complicates the eversion narrative of a simple lateral out-folding of the neural tube during early development (Butler and Hodos, 2005; Yamamoto et al., 2007; Nieuwenhuys, 2011; Mueller et al., 2011; Porter and Mueller, 2020). For instance, eversion models currently do not adequately account for differential timing in the development of different telencephalic areas.

The relative size of different telencephalic domains changes dramatically over the first weeks of development. For instance, early on, the nascent olfactory bulbs constitute 
much of the telencephalon whereas there is disproportionate, massive expansion of the pallial telencephalic lobes from 5dpf to 20dpf. Within the expanding pallium, Dirian et al. (2014) found two distinct populations of neural stem cells that are segregated in space: a dorsomedial domain and a lateral domain. Consistent with late expansion of pallial territories, the lateral domain that contributes neurons to the lateral domain of the pallium, Dl, only becomes neurogenic from 5dpf onwards.

Following morphogenesis of the ventricle, tangential growth of the ventricular zone, driven by telencephalic neuronal differentiation, may be one of the driving forces to expand the pallial ventricular surface (Aboitiz and Montiel, 2019; present results). By 5dpf, the zebrafish telencephalon shows everted morphology (Folgueira et al., 2012; present results), but there is a subsequent expansion of the telencephalic ventricular zone, which grows in lockstep with general telencephalic lobe growth. Cells are added in an outside-in manner following a "sequential stacking" mode, with neurons arranged in age-related layers surrounding a central "core" of earliest-born neurons (Furlan et al., 2017). This addition of newborn cells towards the pallial ventricular surface may force tangential expansion of the ventricular zone as the telencephalon grows. We have observed that EGFP expression in Et(gata2:EGFP) $)^{\text {bi105 }}$ larvae appears to represent post-mitotic telencephalic cells, thus, the first cells to express EGFP in this line probably constitute this central "core".

\section{3. gata2:EGFP ${ }^{\text {bi105 }}+$ pallial neuron morphologies}

Using a Crispr-based labelling technique, we revealed morphologies of cell types in the pallium and subpallium of 6dpf larvae. We observed two different cell types in the pallium by 6dpf that, despite the early age of the animals, show quite elaborate spiny dendritic arbours, similar to those reported in adult fish. Studies in various adult teleosts have shown different neuronal cell types occupying different areas of the pallium (Demski and Beaver, 2001; Demski, 2013). Deep pallial territories host large efferent projection neurons, while periventricular neurons are predominantly small stellate shaped cells (Demski and Beaver, 2001; Demski, 2013). These findings match well with the cell types described in this study. Stellate cells reported here, for instance, resemble the morphology of interneurons present in lateral and medial regions (Dm) of the pallium in adult fish (Yamane et al., 1996; Demski and Beaver, 2001; Giassi et al., 2012; see Demski, 2013 for a review). Thus, even at early stages, differentiated pallial neurons already show complex arborisation, indicative of being integrated in active neural circuits. 


\subsection{Establishment of neural circuits and the emergence of control of behaviours in the telencephalon}

The adult telencephalon is involved in many functions, such as motor control, sensory processing, memory, learning, emotions and social interaction. What is the sequence of maturation of the telencephalic circuits involved in these functions? Our results indicate differentiation of neurons in the olfactory bulb first, while areas of the pallium and subpallium show considerable expansion after $5 \mathrm{dpf}$ suggesting late maturation of these regions. This is in agreement with behavioural studies, which have shown that complex behaviours appear from 2 to 6 weeks post-fertilization (Valente et al., 2012; Aoki et al., 2013; Cheng et al., 2014; Dreosti et al., 2015; Lal et al., 2018; Stednitz et al., 2018; Tunbak et al., 2020; Bartoszek et al., 2021). As a consequence, most functional studies likely involving the role of the telencephalon, such as fear conditioning, social interaction, learning and memory, performed on older zebrafish.

Despite late maturation of some telencephalic circuits, the animal needs to process information from the environment and coordinate movement from an early age. By 4dpf, the larva has already hatched and is transitioning into independent feeding. In this sense, we observed quite mature cell morphologies already by $2 \mathrm{dpf}$ in the olfactory bulb, indicative of early olfactory processing. We also observed that telencephalic gata2:EGFP + cells show complex morphologies and connections by 5-6dpf. In the case of the subpallial gata2:EGFP+ cells, by 6dpf they already show a complex connection patter with caudal regions, which resembles the connections described in the adult for the subpallium (Rink and Wullimann, 2004). Thus, from an early age, this circuit might allow the young animal to exert telencephalic control over certain behaviours.

\section{5. gata2:EGFP+ subpallial cells may be part of the zebrafish septum}

Various cell populations and nuclei in the zebrafish subpallium have been described based on topographical location and neurochemistry. Among these, the ventral area (Vv) and the lateral area $(\mathrm{Vl})$ of the subpallium are proposed to be homologous to septal areas in tetrapods (Rink and Wullimann, 2004; Wullimann and Mueller, 2004b; Ganz et al., 2011; Baeuml et al, 2019). Here we were able to follow the development of a gata2:EGFP+ subpallial cluster located at pre-commisural and commissural levels of the zebrafish telencephalon and analyse its connections. We identify gata2:EGFP+ subpallial cells with elaborate dendritic arbors that span around the anterior commissure and axons that bifurcate and project unilaterally or bilaterally to tuberal and hypothalamic areas. These cell 
populations could correspond, at least partially, with early-migrated telencephalic area M4 (see Mueller and Wullimann, 2005; Mueller et al., 2008). Previously we showed the prethalamic origin of another group subpallial cells in the zebrafish pallium (see Turner et al., 2016). On the contrary, we did not analyse cell migrations into the telencephalon in the present study, so we cannot comment on the exact origin of the subpallial gata2:EGFP+ cells, or, for that matter, any other population in the telencephalon.

Based on location and projection pattern, we believe gata2:EGFP+ subpallial cells could correspond to septal cholinergic populations described in the lateral subpallium of adult zebrafish (Mueller et al., 2004) and other teleosts (trout: Pérez et al., 2000). Both subpallial gata2:EGFP+ cells and cells immunoreactive for choline acetyl transferase (ChAT) share similar location in Vl and similar projection pattern to the hypothalamus (Mueller and Wullimann, 2004; Rink and Wullimann, 2004). Cholinergic cells also show varicose fibers in the subpallium, especially dense around the anterior commissure (Mueller and Wullimann, 2004), similar to the gata2:EGFP+ subpallial cells described in this study. We do not think that the location of the subpallial gata2:EGFP+ cells correspond with neuropeptide $\mathrm{Y}+$ cells previously described in V1 (Castro et al., 2006; Turner et al., 2016), which project to the dorsomedial pallium (not shown), or with the proper entopeduncular nucleus (former ventral entopeduncular nucleus; Turner et al., 2016). In any case, we have not looked at colocalization of either neuropeptide $\mathrm{Y}$ or ChAT in $\operatorname{Et}(\text { gata2:EGFP })^{\text {bi105 }}$ fish, so the putative identity of these gata2:EGFP+ subpallial neurons remains speculative. The heterogeneity of cell types in the lateral subpallium indicates that further detailed analysis is needed to dissect nucleus identity, anatomy, connectivity and development of this area.

\section{6. egr 3 expression and function, future directions for looking at telencephalic activity}

The insertion point in Et(gata2:EGFP) $)^{\text {bi105 }}$ fish is $7 \mathrm{~kb}$ upstream of the first exon of Early Growth Response 3 gene (egr3). Although so far we have used this transgenic line for neuroanatomical studies only (Folgueira et al., 2012; Turner et al., 2016; present study), we believe it will be a useful tool for toher analyses. Although the line expresses a stable form of EGFP, the CRISPR-Cas9 switching method (Auer et al., 2014; Kimura et al., 2014) could be used to convert this EGFP transgene to Gal4 to generate a more versatile transgenic line for such studies. Our results, using this method to interrogate single cell morphology, already show that the eGFP sgRNAs can effectively lead to transgene replacement.

egr3 is a member of the immediate early gene (IEG) family that encodes transcription factors with almost identical zinc finger DNA binding domains (O’Donovan et al., 1999). 
Among other functions, IEGs such as egrl, egr2/krox20, egr3 and egr4 have been implicated in neural plasticity in response to neuronal activation (Li et al., 2005, 2007; Kim et al., 2012). In mice, egr3 expression is induced by synaptic activity and is required for hippocampal long-term potentiation and long-term depression (Gallitano-Mendel et al., 2007), as well as for hippocampal and amygdala dependant learning and memory ( $\mathrm{Li}$ et al., 2007). The persistent expression of egr 3 in spatially restricted populations of CNS cells from early stages (this study, Deguchi et al., 2009) suggests that in addition to roles in synaptic plasticity, the gene may also have a role in early neuronal differentiation or function. Indeed, a closely related gene egr2/krox20, is required for normal rhombomere development (MechtaGrigoriou et al., 2000).

\section{Abbreviations}

ac, anterior commissure;

AIS, anterior intra-telencephalic sulcus;

CC, corpus cerebelli;

chor, horizontal commissure;

Di, diencephalon;

E, eye;

$\mathrm{EG}$, eminentia granularis;

EmT, eminentia thalami;

$\mathrm{fb}$, forebrain bundle;

GC, granularis cerebelli;

$\mathrm{Hb}$, habenula;

HL, lateral hypothalamic lobe;

Hyp, hypothalamus;

$1 \mathrm{Hb}$, left habenula;

lfb, lateral forebrain bundle;

LLF, lateral longitudinal fascicle;

lot, lateral olfactory tract;

LX, vagal lobe;

mlf, medial longitudinal fascicle;

MO, medulla oblongata;

MR, median raphe; 
$\mathrm{OB}$, olfactory bulb;

Och, optic chiasm;

Oe, olfactory epithelium;

OT, optic tectum;

OTn, optic tectum neuropil

$\mathrm{P}$, pineal organ;

Pal, pallium;

PG, preglomerular complex;

PGZ, periventricular grey zone;

PHL, posterior hypothalamic lobe;

PO, preoptic region;

ppn, parapineal organ;

PrT, pretectum;

$\mathrm{PT}$, posterior tuberculum;

PTh, prethalamus;

PTN, posterior tuberal nucleus;

$\mathrm{rHb}$, right habenula;

$\mathrm{RF}$, reticular formation;

sm, stria medullaris;

SR, superior raphe;

SubP, subpallium;

Tel, telencephalic lobes;

$\mathrm{TL}$, torus longitudinalis;

TLa, torus lateralis hypothalami;

vENT, ventral entopeduncular nucleus;

$\mathrm{Vv}$, ventral area of the subpallium;

VIII, $8^{\text {th }}$ cranial nerve root. 


\section{Literature}

Aboitiz, F., Montiel, J.F. (2019). Morphological evolution of the vertebrate forebrain: From mechanical to cellular processes. Evol Dev, 21:330-41. doi: 10.1111/ede.12308.

Aleström, P., D’Angelo, L., Midtlyng, P. J., Schorderet, D. F., Schulte-Merker, S., Sohm, F., \& Warner, S. (2020). Zebrafish: Housing and husbandry recommendations. Laboratory Animals, 54: 213-24. doi: 10.1177/0023677219869037

Aoki, T., Kinoshita, M., Aoki, R., Agetsuma, M., Aizawa, H., Yamazaki, M., Takahoko, M.,

Amo, R., Arata, A., Higashijima, S. (2013). Imaging of neural ensemble for the retrieval of a learned behavioral program. Neuron, 78: 881-94. doi: 10.1016/j.neuron.2013.04.009

Arrenberg, A. B., Driever, W. (2013). Integrating anatomy and function for zebrafish circuit analysis. Front Neural Circuits, 7: 74. doi: 10.3389/fncir.2013.00074.

Auer, T.O., Duroure, K., De Cian, A., Concordet, J.P., and Del Bene, F. (2014). Highly efficient CRISPR/Cas9-mediated knock-in in zebrafish by homology-independent DNA repair. Genome research, 24: 142-53.

Avants, B. B., Tustison, N. J., Song, G., Cook, P. A., Klein, A., and Gee, J. C. (2011). A reproducible evaluation of ANTs similarity metric performance in brain image registration. Neuroimage, 54: 2033-2044. Doi: 10.1016/j.neuroimage.2010.09.025

Baeuml, S. W., Biechl, D., Wullimann, M. F. (2019). Adult islet1 expression outlines ventralized derivatives along zebrafish neuraxis. Front Neuroanat, 13: 19. doi: 10.3389/fnana.2019.00019.

Bartoszek, E. M., Ostenrath, A. M., Jetti, S. K., Serneels, B., Mutlu, A. K., Chau, K. T. P., Yaksi, E. (2021). Ongoing habenular activity is driven by forebrain networks and modulated by olfactory stimuli. Curr Biol, 31: 3861-3874.e3. doi: 10.1016/j.cub.2021.08.021.

Braford, M. R. Jr. (2009). Stalking the everted telencephalon: comparisons of forebrain organization in basal ray-finned fishes and teleosts. Brain Behav Evol, 74: 56-76. doi: $10.1159 / 000229013$.

Briscoe, S. D., Ragsdale, C. W. (2019). Evolution of the Chordate Telencephalon. Curr Biol, 29: R647-R662. doi: 10.1016/j.cub.2019.05.026. 
Bryson-Richardson, R. J., Berger, S., Schilling, T. F., Hall, T. E., Cole, N. J., Gibson, A. J., Sharpe, J., Currie, P. D. (2007). FishNet: an online database of zebrafish anatomy. BMC Biol, 5:34. doi: 10.1186/1741-7007-5-34.

Butler, A. B. (2000). Topography and topology of the teleost telencephalon: a paradox resolved. Neurosci Lett, 293: 95-8. doi: 10.1016/s0304-3940(00)01497-x.

Butler, A. B., Hodos, W. (2005). Comparative vertebrate neuroanatomy. Evolution and adaptation. New York: Wiley-Liss.

Cheng, R. -K., Jesuthasan, S. J., Penney, T. B. (2014). Zebrafish forebrain and temporal conditioning. Philos. Trans. R. Soc. Lond. B, Biol. Sci. 369: 20120462. Doi: $10.1098 /$ rstb.2012.0462

Chitnis, A. B., Kuwada, J. Y. (1990). Axonogenesis in the brain of zebrafish embryos. $J$ Neurosci, 10: 1892-1905. doi: 10.1523/JNEUROSCI.10-06-01892.1990

Castro, A., Becerra, M., Manso, M. J., Anadón, R. (2006). Calretinin immunoreactivity in the brain of the zebrafish, Danio rerio: distribution and comparison with some neuropeptides and neurotransmitter-synthesizing enzymes. I. Olfactory organ and forebrain. J Comp Neurol. 494: 435-59.

Deguchi, T., Fujimori, K. E., Kawasaki, T., Xianghai, L., Yuba, S. (2009). Expression patterns of the Egrl and Egr3 genes during medaka embryonic development. Gene Expr Patterns. 9: 209-14. doi: 10.1016/j.gep.2008.12.004.

Demski, L. S. (2013). The pallium and mind/behavior relationships in teleost fishes. Brain Behav Evol, 82: 31-44. doi: 10.1159/000351994.

Demski, L., and Beaver, J. (2001). Brain and cognitive function in teleost fishes. In: Brain Evolution and Cognition, G. Roth, and M. Wullimann, eds. (Wiley), pp. 297-332.

Dirian, L., Galant, S., Coolen, M., Chen, W., Bedu, S., Houart, C., Bally-Cuif, L., Foucher, I. (2014). Spatial regionalization and heterochrony in the formation of adult pallial neural stem cells. Dev Cell, 30: 123-36. doi: 10.1016/j.devcel.2014.05.012.

Dreosti, E., Lopes, G., Kampff, A. R., Wilson, S.W. (2015). Development of social behavior in young zebrafish. Front Neural Circuits, 9: 39. doi: 10.3389/fncir.2015.00039.

Englund, C., Fink, A., Lau, C., Pham, D., Daza, R.A., Bulfone, A., Kowalczyk, T., Hevner, R.F. (2005). Pax6, Tbr2, and Tbr1 are expressed sequentially by radial glia, intermediate progenitor cells, and postmitotic neurons in developing neocortex. $J$ Neurosci, 25: 247-51. doi: 10.1523/JNEUROSCI.2899-04.2005. 
Feierstein, C. E., Portugues, R., Orger, M. B. (2015). Seeing the whole picture: a comprehensive imaging approach to functional mapping of circuits in behaving zebrafish. Neuroscience, 296: 26-38. doi: 10.1016/j.neuroscience.2014.11.046.

Förster, D., Arnold-Ammer, I., Laurell, E., Barker, A. J., Fernandes, A. M., Finger-Baier, K., Filosa, A., Helmbrecht, T. O., Kölsch, Y., Kühn, E., Robles, E., Slanchev, K., Thiele, T. R., Baier, H., Kubo, F. (2017). Genetic targeting and anatomical registration of neuronal populations in the zebrafish brain with a new set of BAC transgenic tools. Sci Rep, 7: 5230. doi: 10.1038/s41598-017-04657-x.

Förster, D., Kramer, A., Baier, H., Kubo, F. (2018). Optogenetic precision toolkit to reveal form, function and connectivity of single neurons. Methods, 150: 42-48. doi: 10.1016/j.ymeth.2018.08.012.

Folgueira, M., Bayley, P., Navratilova, P., Becker, T. S., Wilson, S. W., Clarke, J. D. (2012). Morphogenesis underlying the development of the everted teleost telencephalon. Neural Dev, 7: 32. doi: 10.1186/1749-8104-7-32. Erratum in: Neural Dev. 2015;10:22.

Furlan, G., Cuccioli, V., Vuillemin, N., Dirian, L., Muntasell, A. J., Coolen, M., Dray, N., Bedu, S., Houart, C., Beaurepaire, E., Foucher, I., Bally-Cuif, L. (2017). Life-long neurogenic activity of individual neural stem cells and continuous growth establish an outside-in architecture in the teleost pallium. Curr Biol, 27:3288-3301.e3. doi: 10.1016/j.cub.2017.09.052.

Gage, S. P. (1893). The brain of Diemyctilis viridescens from larval to adult life and comparison with the brain of Amia and of Petromyzon. In: The Wilder QuarterCentury Book, pp 259-313. Ithaca, NY: Comstock Publ Co.

Gallitano-Mendel, A., Izumi, Y., Tokuda, K., Zorumski, C. F., Howell, M.P., Muglia, L. J., Wozniak, D. F., Milbrandt, J. (2007). The immediate early gene early growth response gene 3 mediates adaptation to stress and novelty. Neuroscience, 148: 633643. doi: 10.1016/j.neuroscience.2007.05.050.

Ganz, J., Kaslin, J., Freudenreich, D., Machate, A., Geffarth, M., Brand, M. (2012). Subdivisions of the adult zebrafish subpallium by molecular marker analysis. J Comp Neurol, 520: 633-55. doi: 10.1002/cne.22757.

Giassi, A. C., Harvey-Girard, E., Valsamis, B., Maler, L. (2012). Organization of the gymnotiform fish pallium in relation to learning and memory: I. Cytoarchitectonics and cellular morphology. J Comp Neurol, 520: 3314-37. doi: 10.1002/cne.23097. 
Giudicelli, F., Gilardi-Hebenstreit, P., Mechta-Grigoriou, F., Poquet, C., Charnay, P. (2003). Novel activities of Mafb underlie its dual role in hindbrain segmentation and regional specification. Dev Biol, 253:150-62. doi: 10.1006/dbio.2002.0864.

Herget, U., Wolf, A., Wullimann, M.F., Ryu, S. (2014). Molecular neuroanatomy and chemoarchitecture of the neurosecretory preoptic-hypothalamic area in zebrafish larvae. J Comp Neurol, 522:1542-64. doi: 10.1002/cne.23480. Erratum in: J Comp Neurol. (2014), 522:3139.

Hevner, R.F. (2006). From radial glia to pyramidal-projection neuron: transcription factor cascades in cerebral cortex development. Mol Neurobiol, 33:33-50. doi: 10.1385/MN:33:1:033.

Hevner, R.F., Shi, L., Justice, N., Hsueh, Y., Sheng, M., Smiga, S., Bulfone, A., Goffinet, A.M., Campagnoni, A.T., Rubenstein, J.L. (2001) Tbr1 regulates differentiation of the preplate and layer 6. Neuron, 29:353-66. doi: 10.1016/s0896-6273(01)00211-2. PMID: 11239428.

Higashijima, S., Hotta, Y., Okamoto, H. (2000). Visualization of cranial motor neurons in live transgenic zebrafish expressing green fluorescent protein under the control of the islet-1 promoter/enhancer. J Neurosci, 20: 206-218.

Higashijima, S., Mandel, G., Fetcho, J. R. (2004). Distribution of prospective glutamatergic, glycinergic, and GABAergic neurons in embryonic and larval zebrafish. J Comp Neurol, 480:1-18. doi: 10.1002/cne.20278.

Jao, L. E., Wente, S. R., Chen, W. (2013). Efficient multiplex biallelic zebrafish genome editing using a CRISPR nuclease system. Proc Natl Acad Sci U S A, 110: 13904-9. doi: 10.1073/pnas.1308335110.

Jülich, D., Hwee Lim, C., Round, J., Nicolaije, C., Schroeder, J., Davies, A., Geisler, R., Lewis, J., Jiang, Y.J., Holley, S.A, Tübingen 2000 Screen Consortium. (2005). beamter/deltaC and the role of Notch ligands in the zebrafish somite segmentation, hindbrain neurogenesis and hypochord differentiation. Dev. Biol, 286: 391-404. doi: 10.1016/j.ydbio.2005.06.040

Kawakami, K. (2004) Transgenesis and gene trap methods in zebrafish by using the Tol2 transposable element. Methods Cell Biol, 77: 201-22. doi: 10.1016/s0091679x(04)77011-9. PMID: 15602913.

Kawakami, K., Shima, A., Kawakami, N. (2000). Identification of a functional transposase of the Tol2 element, an Ac-like element from the Japanese medaka fish, and its 
transposition in the zebrafish germ lineage. Proc Natl Acad Sci U S A, 97: 11403-8. doi: 10.1073/pnas.97.21.11403.

Kawakami, K., Abe, G., Asada, T., Asakawa, K., Fukuda, R., Ito, A., Lal, P., Mouri, N., Muto, A., Suster, M. L., Takakubo, H., Urasaki, A., Wada, H., Yoshida, M. (2010). zTrap: zebrafish gene trap and enhancer trap database. BMC Dev Biol, 10: 105. doi: 10.1186/1471-213X-10-105.

Kenney, J. W., Steadman, P. E., Young, O., Shi, M. T., Polanco, M., Dubaishi, S., Covert, K., Mueller, T., Frankland, P. W. (2021). A 3D adult zebrafish brain atlas (AZBA) for the digital age. Elife, 10: e69988. doi: 10.7554/eLife.69988.

Kim, J. H., Roberts, D. S., Hu, Y., Lau, G. C., Brooks-Kayal, A. R., Farb, D. H., Russek, S. J. (2012). Brain-derived neurotrophic factor uses CREB and Egr3 to regulate NMDA receptor levels in cortical neurons. J Neurochem. 120: 210-29. doi: 10.1111/j.14714159.2011.07555.x.

Kimura, Y., Hisano, Y., Kawahara, A., Higashijima, S. (2014). Efficient generation of knockin transgenic zebrafish carrying reporter/driver genes by CRISPR/Cas9-mediated genome engineering. Sci Rep, 4: 6545. doi: 10.1038/srep06545.

Kimmel, C. B., Ballard, W. W., Kimmel, S. R., Ullmann, B., and Schilling, T. F. (1995). Stages of embryonic development of the zebrafish. Dev Dyn, 203: 253-310. doi:10.1002/aja.1002030302

Knapik, E. W., Goodman, A., Ekker, M., Chevrette, M., Delgado, J., Neuhauss, S., Shimoda, N., Driever, W., Fishman, M. C., Jacob, H. J. (1998). A microsatellite genetic linkage map for zebrafish (Danio rerio). Nat Genet, 18: 338-43. doi: 10.1038/ng0498-338.

Kunst, M., Laurell, E., Mokayes, N., Kramer, A., Kubo, F., Fernandes, A. M., Förster, D., Dal Maschio. M., Baier, H. (2019). A cellular-resolution atlas of the larval zebrafish brain. Neuron, 103:21-38.e5. doi: 10.1016/j.neuron.2019.04.034.

Kwan, K. M., Fujimoto, E., Grabher, C., Mangum, B. D., Hardy, M. E., Campbell, D. S., Parant, J. M., Yost, H. J., Kanki, J. P., Chien, C. B. (2007). The Tol2kit: a multisite gateway-based construction kit for Tol2 transposon transgenesis constructs. Dev Dyn, 236: 3088-99. doi: 10.1002/dvdy.21343.

Lal, P., Tanabe, H., Suster, M. L., Ailani, D., Kotani, Y., Muto, A., Itoh, M., Iwasaki, M., Wada, H., Yaksi, E., et al. (2018). Identification of a neuronal population in the telencephalon essential for fear conditioning in zebrafish. BMC Biol, 16: 45.

Leung, L. C., Wang, G. X., Mourrain, P. (2013). Imaging zebrafish neural circuitry from whole brain to synapse. Front Neural Circuits, 7: 76. doi: 10.3389/fncir.2013.00076. 
Li, J., Mack, J. A., Souren, M., Yaksi, E., Higashijima, S., Mione, M., Fetcho, J. R., Friedrich, R. W. (2005). Early development of functional spatial maps in the zebrafish olfactory bulb. J Neurosci, 25: 5784-95. doi: 10.1523/JNEUROSCI.0922-05.2005.

Li, L., Carter, J., Gao, X., Whitehead, J., Tourtellotte, W. G. (2005). The neuroplasticityassociated arc gene is a direct transcriptional target of early growth response (Egr) transcription factors. Mol Cell Biol, 25: 10286-300. doi: 10.1128/MCB.25.23.1028610300.2005 .

Li, L., Yun, S. H., Keblesh, J., Trommer, B. L., Xiong, H., Radulovic, J., Tourtellotte, W. G. (2007). Egr3, a synaptic activity regulated transcription factor that is essential for learning and memory. Mol Cell Neurosci, 35: 76-88. doi: 10.1016/j.mcn.2007.02.004.

MacDonald, R. B., Debiais-Thibaud, M., Talbot, J. C., Ekker, M. (2010). The relationship between $d l x$ and gadl expression indicates highly conserved genetic pathways in the zebrafish forebrain. Dev Dyn, 239: 2298-306. doi: 10.1002/dvdy.22365.

Marquart, G. D., Tabor, K. M., Brown, M., Strykowski, J. L., Varshney, G. K., LaFave, M. C., Mueller, T., Burgess, S. M., Higashijima, S., Burgess, H. A. (2015). A 3D searchable database of transgenic sebrafish Gal4 and Cre Lines for functional neuroanatomy studies. Front Neural Circuits, 9: 78. doi: 10.3389/fncir.2015.00078.

Marquart, G. D., Tabor, K. M., Horstick, E. J., Brown, M., Geoca, A. K., Polys, N. F., Nogare, D. D., Burgess, H. A. (2017). High-precision registration between zebrafish brain atlases using symmetric diffeomorphic normalization. GigaScience, 6: 1-15. doi: 10.1093/gigascience/gix056.

Mechta-Grigoriou, F., Garel, S., Charnay, P. (2000). Nab proteins mediate a negative feedback loop controlling Krox-20 activity in the developing hindbrain. Development. 127: 119-28.

Meek, J., Schellart, N. A. (1978). A Golgi study of goldfish optic tectum. J CompNeurol, 182: 89-122.

Mione, M., Shanmugalingam, S., Kimelman, D., Griffin, K. (2001). Overlapping expression of zebrafish T-brain-1 and eomesodermin during forebrain development. Mech Dev, 100: 93-7. doi: 10.1016/s0925-4773(00)00501-3.

Miyasaka, N., Morimoto, K., Tsubokawa, T., Higashijima, S., Okamoto, H., Yoshihara, Y. (2009). From the olfactory bulb to higher brain centers: genetic visualization of secondary olfactory pathways in zebrafish. $J$ Neurosci, 29: 4756-67. doi: 10.1523/JNEUROSCI.0118-09.2009. 
Miyasaka, N., Arganda-Carreras, I., Wakisaka, N., Masuda, M., Sümbül, U., Seung, H. S., Yoshihara, Y. (2014). Olfactory projectome in the zebrafish forebrain revealed by genetic single-neuron labelling. Nat Commun, 5: 3639. doi: 10.1038/ncomms4639.

Mueller, T., Guo, S. (2009). The distribution of GAD67-mRNA in the adult zebrafish (teleost) forebrain reveals a prosomeric pattern and suggests previously unidentified homologies to tetrapods. J Comp Neurol, 516: 553-68. doi: 10.1002/cne.22122.

Mueller, T., Vernier, P., Wullimann, M. F. (2004). The adult central nervous cholinergic system of a neurogenetic model animal, the zebrafish Danio rerio. Brain Res, 1011: 156-69. doi: 10.1016/j.brainres.2004.02.073.

Mueller, T., Vernier, P., Wullimann, M.F. (2006). A phylotypic stage in vertebrate brain development: GABA cell patterns in zebrafish compared with mouse. J Comp Neurol, 494: 620-34. doi: 10.1002/cne.20824.

Mueller, T., Wullimann, M. F., Guo, S. (2008). Early teleostean basal ganglia development visualized by zebrafish Dlx2a, Lhx6, Lhx7, Tbr2 (eomesa), and GAD67 gene expression. J Comp Neurol, 507: 1245-57. doi: 10.1002/cne.21604.

Mueller, T., Dong, Z., Berberoglu, M. A., Guo, S. (2011). The dorsal pallium in zebrafish, Danio rerio (Cyprinidae, Teleostei). Brain Res, 1381: 95-105. doi: 10.1016/j.brainres.2010.12.089.

Mueller, T., Wullimann. M. F. (2005). Atlas of early zebrafish brain development. A tool for molecular neurogenetics. 2nd Edition. ISBN 9780124186699.

Mueller, T., Wullimann, M.F. (2009). An evolutionary interpretation of teleostean forebrain anatomy. Brain Behav Evol, 74: 30-42. doi: 10.1159/000229011.

Nieuwenhuys, R. (2009a) The forebrain of actinopterygians revisited. Brain Behav Evol 73, 229-52. doi: 10.1159/000225622

Nieuwenhuys, R. (2009b). On old and new comparative neurological sinners: the evolutionary importance of the membranous parts of the actinopterygian forebrain and their sites of attachment. J Comp Neurol, 516: 87-93. doi: 10.1002/cne.22106.

Nieuwenhuys, R. (2011). The development and general morphology of the telencephalon of actinopterygian fishes: synopsis, documentation and commentary. Brain Struct Funct, 215:141-57. doi: 10.1007/s00429-010-0285-6.

Northcutt, R. G. (2008). Forebrain evolution in bony fishes. Brain Res Bull, 75: 191-205. doi: 10.1016/j.brainresbull.2007.10.058. 
O'Donovan, K.J., Tourtellotte, W.G., Millbrandt, J., Baraban, J.M. (1999). The EGR family of transcription-regulatory factors: progress at the interface of molecular and systems neuroscience. Trends Neurosci, 22: 167-73. doi: 10.1016/s0166-2236(98)01343-5.

Pérez, S. E., Yáñez, J., Marín, O., Anadón, R., González, A., Rodríguez-Moldes, I. (2000). Distribution of choline acetyltransferase (ChAT) immunoreactivity in the brain of the adult trout and tract-tracing observations on the connections of the nuclei of the isthmus. $J$ Comp Neurol, 428: 450-74. doi: 10.1002/10969861(20001218)428:3<450::aid-cne5>3.0.co;2-t.

Porter, B.A., Mueller, T. (2020). The Zebrafish Amygdaloid Complex - Functional Ground Plan, Molecular Delineation, and Everted Topology. Front Neurosci.14: 608. doi: 10.3389/fnins.2020.00608.

Puelles, L., and Rubenstein, J. L. (2003). Forebrain gene expression domains and the evolving prosomeric model. Trends Neurosci, 26: 469-476. doi: 10.1016/s01662236(03)00234-0

Puelles, L., and Rubenstein, J. L. (2015). A new scenario of hypothalamic organization: rationale of new hypotheses introduced in the updated prosomeric model. Front. Neuroanat, 9: 27. doi: 10.3389/fnana.2015.00027

Puelles, L., Kuwana, E., Puelles, E., Bulfone, A., Shimamura, K., Keleher, J., Smiga, S., Rubenstein, J.L. (2000). Pallial and subpallial derivatives in the embryonic chick and mouse telencephalon, traced by the expression of the genes Dlx-2, Emx-1, Nkx-2.1, Pax-6, and Tbr-1. J Comp Neurol. 424:409-38.

Rink, E., Wullimann, M. F. (2004). Connections of the ventral telencephalon (subpallium) in the zebrafish (Danio rerio). Brain Res, 1011:206-20. doi: 10.1016/j.brainres.2004.03.027.

Robles, E. (2017). The power of projectomes: genetic mosaic labeling in the larval zebrafish brain reveals organizing principles of sensory circuits. J Neurogenet, 31: 61-9. doi: 10.1080/01677063.2017.1359834.

Robles, E., Smith, S. J., Baier, H. (2011). Characterization of genetically targeted neuron types in the zebrafish optic tectum. Front Neural Circuits, 5:1. doi: 10.3389/fncir.2011.00001.

Ronneberger, O., Liu, K., Rath, M., Rue $\beta$, D., Mueller, T., Skibbe, H., Drayer, B., Schmidt, T., Filippi, A., Nitschke, R., Brox, T., Burkhardt, H., Driever, W. (2012). ViBE-Z: a framework for 3D virtual colocalization analysis in zebrafish larval brains. Nat 
Methods, 9:735-42. doi: 10.1038/nmeth.2076. Erratum in: Nat Methods (2012), 9:1031

Scott, E. K. (2009). The Gal4/UAS toolbox in zebrafish: new approaches for defining behavioral circuits. $J$ Neurochem, 110: 441-56. doi: 10.1111/j.14714159.2009.06161.x.

Scott, E. K., Mason, L., Arrenberg, A. B., Ziv, L., Gosse, N. J., Xiao, T., Chi, N.C., Asakawa, K., Kawakami, K., Baier, H. (2007). Targeting neural circuitry in zebrafish using GAL4 enhancer trapping. Nat Methods, 4: 323-6. doi: 10.1038/nmeth1033.

Shanmugalingam, S., Houart, C., Picker, A., Reifers, F., Macdonald, R., Barth, A., Griffin, K., Brand, M., Wilson, S. W. (2000). Ace/Fgf8 is required for forebrain commissure formation and patterning of the telencephalon. Development 12, 2549-61.

Stednitz, S. J., McDermott, E. M., Ncube, D., Tallafuss, A., Eisen, J. S. and Washbourne, P. (2018). Forebrain control of behaviorally driven social orienting in zebrafish. Curr. Biol, 28: 2445-51.e3.

Studnička, F. K. (1894) Zur Lösung einiger fragen aus der morphologie des vorderhirnes der vranioten. Anat Anz 9: 307-20.

Studnička, F. K. (1896) Beiträge zur anatomie und entwicklungsgeschichte des vorderhirns der vranioten. Sitzungsber K-Böhm Gesellsch Wissensch Mathem Naturw K1 15: 132.

Suster, M. L., Abe, G., Schouw, A., Kawakami, K. (2011). Transposon-mediated BAC transgenesis in zebrafish. Nat Protoc, 6:1998-2021. doi: 10.1038/nprot.2011.416.

Tabor, K. M., Marquart, G. D., Hurt, C., Smith, T.S., Geoca, A. K., Bhandiwad, A. A., Subedi, A., Sinclair, J. L., Rose, H. M., Polys, N. F., Burgess, H. (2019). A brainwide cellular resolution imaging of Cre transgenic zebrafish lines for functional circuit-mapping. Elife, 8:e42687. doi: 10.7554/eLife.42687.

Takeuchi, M., Matsuda, K., Yamaguchi, S., Asakawa, K., Miyasaka, N., Lal, P., Yoshihara, Y., Koga, A., Kawakami, K., Shimizu, T., Hibi, M. (2015). Establishment of Gal4 transgenic zebrafish lines for analysis of development of cerebellar neural circuitry. Dev Biol, 397: 1-17. doi: 10.1016/j.ydbio.2014.09.030.

Tunbak, H., Vazquez-Prada, M., Ryan, T. M., Kampff, A. R., Dreosti, E. (2020). Wholebrain mapping of socially isolated zebrafish reveals that lonely fish are not loners. Elife, 9: e55863. doi: 10.7554/eLife.55863.

Turner, K., Bracewell, T., Hawkins, T. A. (2014). Anatomical dissection of zebrafish brain development. Methods Mol Biol, 1082. doi: 10.1007/978-1-62703-655-9_14 
Turner, K. J., Hawkins, T. A., Yáñez, J., Anadón, R., Wilson, S. W., Folgueira, M. (2016). Afferent connectivity of the zebrafish habenulae. Front Neural Circuits, 10: 30. doi: 10.3389/fncir.2016.00030.

Ullmann, J. F., Cowin, G., Kurniawan, N. D., Collin, S. P. (2010). A three-dimensional digital atlas of the zebrafish brain. Neuroimage, 51: 76-82. doi: 10.1016/j.neuroimage.2010.01.086.

Valente, A., Huang, K. H., Portugues, R., Engert, F. (2012). Ontogeny of classical and operant learning behaviors in zebrafish. Learn Mem, 19: 170-7. doi: 10.1101/lm.025668.112.

Vanegas, H., Laufer, M., and Amat, J. (1974). The optic tectum of a perciform teleost. I. General configuration and cytoarchitecture. J. Comp. Neurol, 154: 43-60. doi: 10.1002/cne.901540104

Westerfield, M. (2000). The Zebrafish Book. A Guide for the Laboratory Use of Zebrafish (Danio rerio). 4th Edition. University of Oregon Press, Eugene.

Wilson, S. W., Ross, L. S., Parrett, T., Easter, S. S. (1990). The development of a simple scaffold of axon tracts in the brain of the embryonic zebrafish, Brachydanio rerio. Development, 108: 121-45.

Wullimann, M.F., Mueller, T. (2004a). Identification and morphogenesis of the eminentia thalami in the zebrafish. J Comp Neurol, 471:37-48. doi: 10.1002/cne.20011.

Wullimann, M. F., Mueller, T. (2004b). Teleostean and mammalian forebrains contrasted: Evidence from genes to behavior. $J$ Comp Neurol, 475: 143-62. doi: 10.1002/cne.20183. Erratum in: J Comp Neurol, (2004). 478: 427-8.

Wullimann, M. F., Rupp, B., Reichert, H., 1996. Neuroanatomy of the zebrafish brain. A topological atlas. Birkhäuser Verlag Basel.

Yamagata, K., Kaufmann, W. E., Lanahan, A., Papapavlou, M., Barnes, C. A., Andreasson, K. I,. Worley, P. F. (1994). Egr3/Pilot, a zinc finger transcription factor, is rapidly regulated by activity in brain neurons and colocalizes with Egr1/zif268. Learn Mem, 1: $140-52$.

Yamamoto, N., Ishikawa, Y., Yoshimoto, M., Xue, H. G., Bahaxar, N., Sawai, N., Yang, C. Y., Ozawa, H., Ito, H. (2007). A new interpretation on the homology of the teleostean telencephalon based on hodology and a new eversion model. Brain Behav. Evol, 69: 96-104. 
Yamane, Y., Yoshimoto, M., Ito, H. (1996). Area dorsalis pars lateralis of the telencephalon in a teleost (Sebastiscus marmoratus) can be divided into dorsal and ventral regions. Brain Behav Evol, 48: 338-49. doi: 10.1159/000113212.

Yáñez, J., Folgueira, M., Lamas, I., Anadón, R. (2021). The organization of the zebrafish pallium from a hodological perspective. J Comp Neurol, Epub ahead of print. doi: 10.1002/cne.25268.

Yu, M., Xi, Y., Pollack, J., Debiais-Thibaud, M., Macdonald, R. B., Ekker, M. (2011). Activity of $d l x 5 a / d l x 6 a$ regulatory elements during zebrafish GABAergic neuron development. Int J Dev Neurosci, 29: 681-91. doi: 10.1016/j.ijdevneu.2011.06.005.

Zhang, C., Gao, J., Zhang, H., Sun, L., and Peng, G. (2012). Robo2-Slit and Dcc-Netrin1 coordinate neuron axonal pathfinding within the embryonic axon tracts. J Neurosci, 32: $12589-602$.

Zerucha, T., Stühmer, T., Hatch, G., Park, B. K., Long, Q., Yu, G., Gambarotta, A., Schultz, J. R., Rubenstein, J. L., Ekker, M. (2000). A highly conserved enhancer in the 5/Dlx6 intergenic region is the site of cross-regulatory interactions between $D l x$ genes in the embryonic forebrain. J Neurosci, 20: 709-21.

\section{Author Contributions}

MF, KJT and TAH conceived and designed the work, with inputs from SWW. MF, KJT, and TAH acquired and analysed the data. PH registered transgenic lines. KT, TAH and LEV developed the single cell labelling with Crispr/Cas9 technique. All authors contributed to interpretation of data and to writing the article. IHB provided comments on the final manuscript.

\section{Funding}

This study was supported by a Wellcome Trust Investigator Award (095722/Z/11/Z) to SW (Orcid ID 0000-0002-8557-5940; loop: s.wilson@ucl.ac.uk); BBSRC funding (BB/H012516/1) to SWW and TAH (Orcid ID 0000-0003-2921-0004). IHB supported by a Sir Henry Dale Fellowship (101195/Z/13/Z) and a Wellcome Senior Research Fellowship (220273/Z/20/Z). PH supported by a UCL IMPACT studentship. FONDECYT funding to LEV(1211508).

\section{Conflict of Interest Statement}


The authors declare that the research was conducted in the absence of any commercial or financial relationships that could be construed as a potential conflict of interest.

\section{Acknowledgments}

We thank members of UCL Fish Facility for help maintaining fish lines, members of our labs in UCL and UDC for discussion and support, Dr. Ramón Anadón for comments on initial draft of the manuscript, Dr. Thomas Auer for his advice and sharing of reagents for the single cell labelling using Crispr, and Dr. Tom Becker for the Et(gata2:GFP) ${ }^{b i 05}$ line.

\section{Data Availability Statement}

Authors are keen for their registered transgenic line data to be used as a tool for other researchers studying the developing telencephalon. Thus, authors will to make all raw data pertaining to this study available upon request. 
bioRxiv preprint doi: https://doi.org/10.1101/2022.03.02.482259; this version posted March 4, 2022. The copyright holder for this preprint (which was not certified by peer review) is the author/funder, who has granted bioRxiv a license to display the preprint in perpetuity. It is made available under aCC-BY-NC-ND 4.0 International license.

\section{Figures}




bioRxiv preprint doi: https://doi.org/10 1101/2022.03 02 482259· this version posted March 4, 2022. The copyright holder for this preprint (which was not certified by peer review) is the author/funder, who has granted bioRxiv a license to display the preprint in perpetuity. It is made available under aCC-BY-NC-ND 4.0 International license.

Figure 1: $\operatorname{Et}(\text { gata2:EGFP })^{\text {bi105 }}$ insertion is located near egr3 and expression of egr3 matches transgene expression. Mapping of Et(gata2:EGFP) ${ }^{\text {bil05 }}$ insertion showing the position of Genome Walker BLAST hits on assembly GRCz11, relative position of neighbouring genes (black lines) and linkage markers with meiotic recombination data (A), the lower blue line in $\mathbf{A}$ indicates the region around egr3 shown in $\mathbf{B}$, with BLAST hits (insertion) locations. C-F": Immunostaining and in situ hybridization showing EGFP and egr3 mRNA co-expression in the telencephalon and optic tectum of Et(gata2:EGFP) ${ }^{\text {bil05 }}$ fish at 48hpf (C-D") and 6dpf (E-F") in frontal view. C-C" and E-E" show z-projections and D-D" and F-F" show single z-slices. Note the co-expression of EGFP and egr3 in pallial (arrows) and subpallial (arrowheads) cells. Scale bars: $50 \mu \mathrm{m}$. 
bioRxiv preprint doi: https://doi.org/10.1101/2022.03.02.482259; this version posted March 4, 2022. The copyright holder for this preprint (which was not certified by peer review) is the author/funder, who has granted bioRxiv a license to display the preprint in perpetuity. It is made available under aCC-BY-NC-ND 4.0 International license.

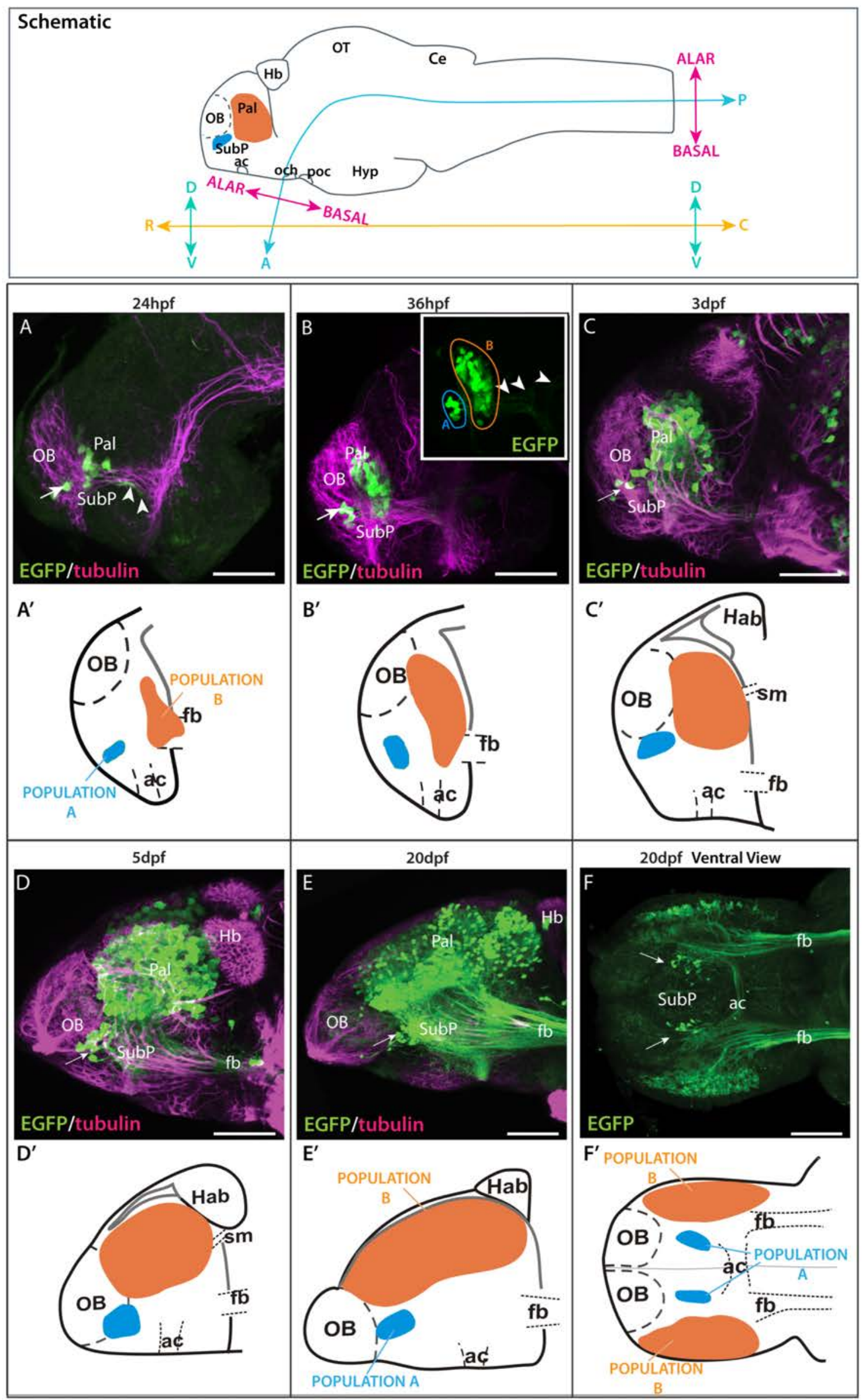


bioRxiv preprint doi: https://doi.org/10.1101/2022.03.02 482259· this version posted March 4, 2022. The copyright holder for this preprint (which was not certified by peer review) is the author/funder, who has granted bioRxiv a license to display the preprint in perpetuity. It is made available under aCC-BY-NC-ND 4.0 International license.

Figure 2: Time series showing Et(gata2:EGFP) $)^{\text {bi105 }}$ expression. Top box: sagittal view of a 3dpf zebrafish larval brain illustrating the body axis coordinates ("rostral", "caudal" "dorsal" and "ventral") predominantly used in this paper (adapted from Herget et al., 2014). For reference, the bent neuraxis of the neural tube is also shown (see Herget et al., 2014) with the Alar/Basal subdivision of the brain defined according to the neuromeric model (Puelles and Rubenstein, 2003, 2015). Lateral (A-E) and ventral (F) views of zebrafish brains stained against EGFP only (B inset, F) or EGFP in combination with acetylated tubulin (A-E) from $24 \mathrm{hpf}$ to $20 \mathrm{dpf}$. Arrow points to the ventral EGFP+ population identified as a subpallial nucleus. Arrowheads in $\mathbf{A}$ and $\mathbf{B}$ inset point to fibres exiting the telencephalon along the forebrain bundle towards caudal areas. A'-F': Schematics showing the changes in location of the EGFP+ populations (A and B) relative to telencephalic regions and tracts over time. Rostral to the left. Scale bars: (A-D) $50 \mu \mathrm{m}$; (E,F) Abbreviations: A, anterior; C, caudal; D, dorsal; P, posterior; V, ventral. $100 \mu \mathrm{m}$. 
bioRxiv preprint doi: https//doi.org/10.1101/2022.03.02.482259; this version posted March 4, 2022. The copyright holder for this preprint (which was not certified by peer review) is the author/funder, who has granted bioRxiv a license to display the preprint in perpetuity. It is made available under aCC-BY-NC-ND 4.0 International license.


Figure 3: $\operatorname{Et}(\text { gata2:EGFP })^{\text {bi105 }}$ line expression in combination with tbr1 and dlx1a markers. Sagittal (A-D') and horizontal (E-H') sections through a 36hpf Et(gata2:EGFP)bi105 fish labelled with anti-GFP (green) and FISH for tbrl (pink)(A,A',C,C',E,E',G,G') or dlxla (pink) (B,B',D,D',F,F',,H,H') with cell nuclei stained with sytox orange (grey). All images are single confocal z-slices taken from volumes, rostral to the left. Scale bars: $50 \mu \mathrm{m}$. 
bioRxiv preprint doi: https://doi.org/10.1101/2022.03.02.482259; this version posted March 4, 2022. The copyright holder for this preprint (which was not certified by peer review) is the author/funder, who has granted bioRxiv a license to display the preprint in perpetuity. It is made available under aCC-BY-NC-ND 4.0 International license.
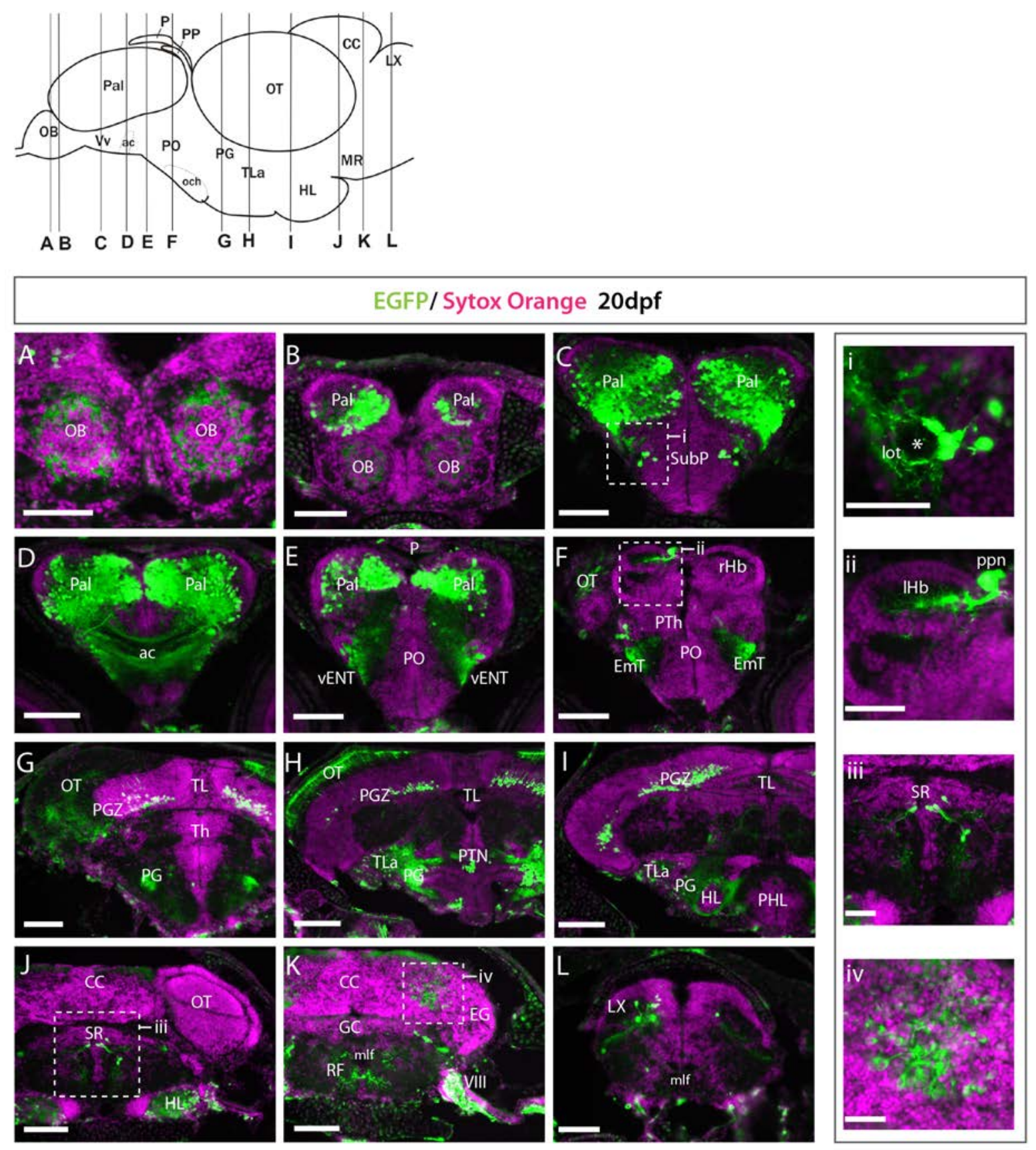

Figure 4:Et(gata2:EGFP) ${ }^{\text {bi105 }}$ expression at 20dpf. A-L: Transverse section through an

Et(gata2:EGFP) $)^{\text {bi105 }}$ fish showing EGFP expression from rostral (A) to caudal areas (L). Schematic of lateral view of the brain (top left) shows levels of the sections. i-iv: detail of the areas marked in $\mathbf{C}, \mathbf{F}, \mathbf{J}$ and $\mathbf{K}$. Areas of EGFP expression at this stage was consistent with those seen at $4 \mathrm{dpf}$; the only de novo expression observed was in the cerebellum and vagal lobe (K, L, iv). Scale bars: (A-L) $100 \mu \mathrm{m}$; (i-iv) $40 \mu \mathrm{m}$. 
bioRxiv preprint doi: https://doi.org/10.1101/2022.03.02.482259; this version posted March 4, 2022. The copyright holder for this preprint (which was not certified by peer review) is the author/funder, who has granted bioRxiv a license to display the preprint in perpetuity. It is made available under aCC-BY-NC-ND 4.0 International license.
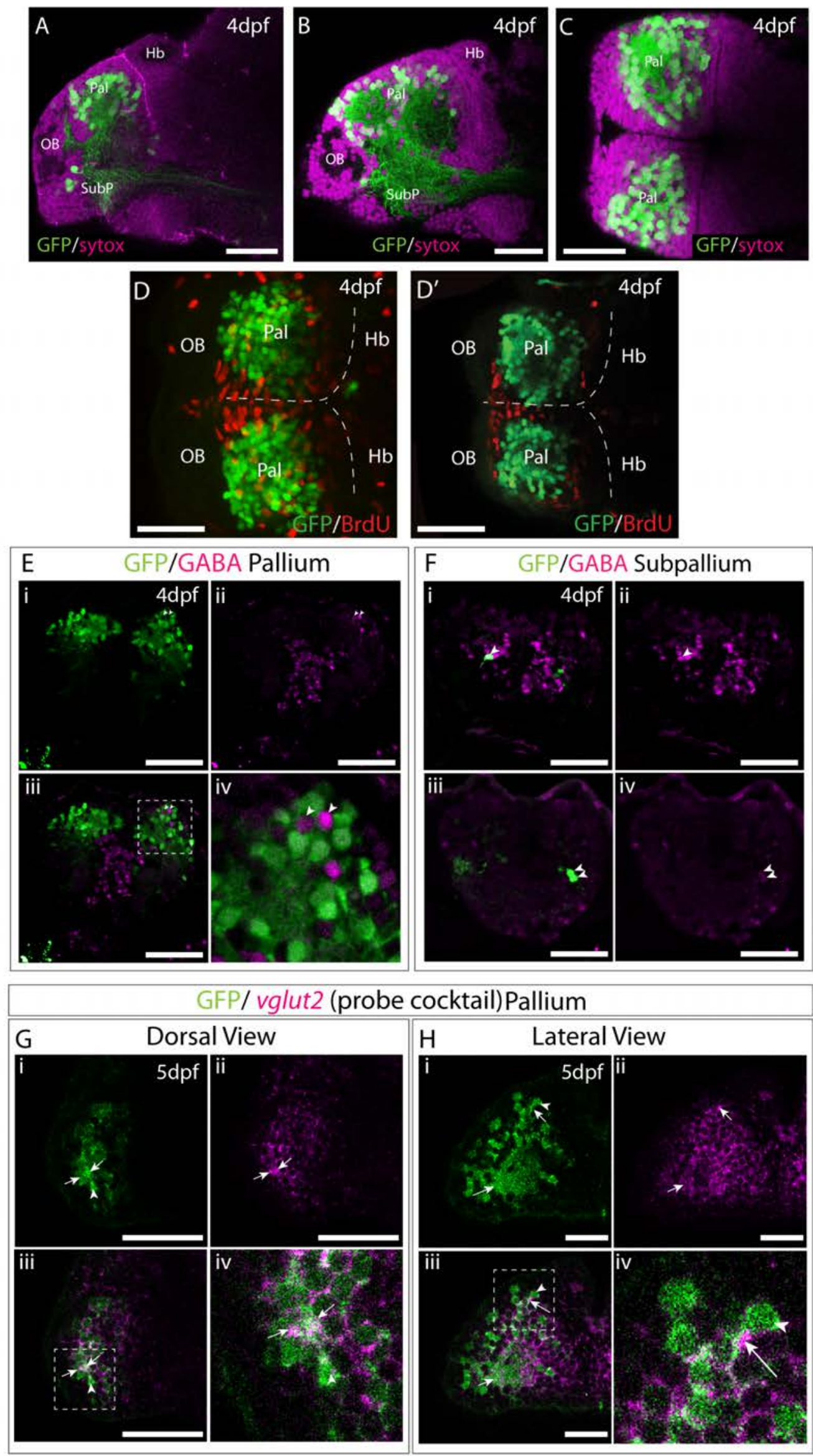
Figure 5: $\operatorname{Et}(\text { gata2:EGFP })^{\text {bi105 }}$ is expressed in post-mitotic glutamatergic telencephalic neurons. Sagittal (A-B) and horizontal (C) sections through a 4dpf Et(gata2:EGFP) bi105 brain stained with sytox (magenta) to label cell nuclei and anti-EGFP (green). EGFP expression is largely excluded from the dorsal and medial ventricular zones of the telencephalon.

D-D': Dorsal views of a 4dpf Et(gata2:EGFP) ${ }^{\text {bi105 }}$ brain labelled with anti-BrdU (red) and anti-GFP (green) antibodies. (D) z-projection and (D') shows a single coronal z-slice through the same brain. BrdU is excluded from the EGFP+ neurons in the dorsal telencephalon indicating that these cells are likely to be non-proliferative and postmitotic.

E-F: Transverse sections through the telencephalon of a $4 \mathrm{dpf} \operatorname{Et}\left(\right.$ gata2:EGFP) ${ }^{\text {bi105 }}$ brain stained with anti-GABA (magenta) to label GABAergic cells and anti-GFP (green). EGFP+ cells in the pallium (E) are for the most part GABA-. Gaps where GABAergic pallial interneurons intermingle with EGFP+ pallial neurons are visible (arrowheads in Ei). In subpallial telencephalic domains (F) some cells do co-express EGFP and GABA (arrowheads in Fi-iv). Fi-ii and Fiii-iv are different z-sections through the same $\mathrm{Et}\left(\right.$ gata2:EGFP) ${ }^{\text {bi105 }}$ brain showing subpallial EGFP+ neurons on both sides of the brain.

Dorsal (G) and lateral (H) views of Et(gata2:EGFP) bi105 brains at $5 \mathrm{dpf}$ labelled with FISH using a "cocktail" probe for vglut2a/slc17a6b and vglut2b/slc17a6a (magenta) and antibody labelling with anti-GFP (green) show overlap of vglut $2 a$ and EGFP within the telencephalic neuropil (arrows) associated with EGFP+ cells (arrowheads). Giv: High-magnification view of dorsal telencephalic neurons in boxed region in Giii. Hiv: High-magnification view of dorsal telencephalic neurons in boxed region in Hiii.

Scale bars: $50 \mu \mathrm{m}$. 
bioRxiv preprint doi: https://doi.org/10.1101/2022.03.02.482259; this version posted March 4, 2022. The copyright holder for this preprint (which was not certified by peer review) is the author/funder, who has granted bioRxiv a license to display the preprint in perpetuity. It is made available under aCC-BY-NC-ND 4.0 International license.
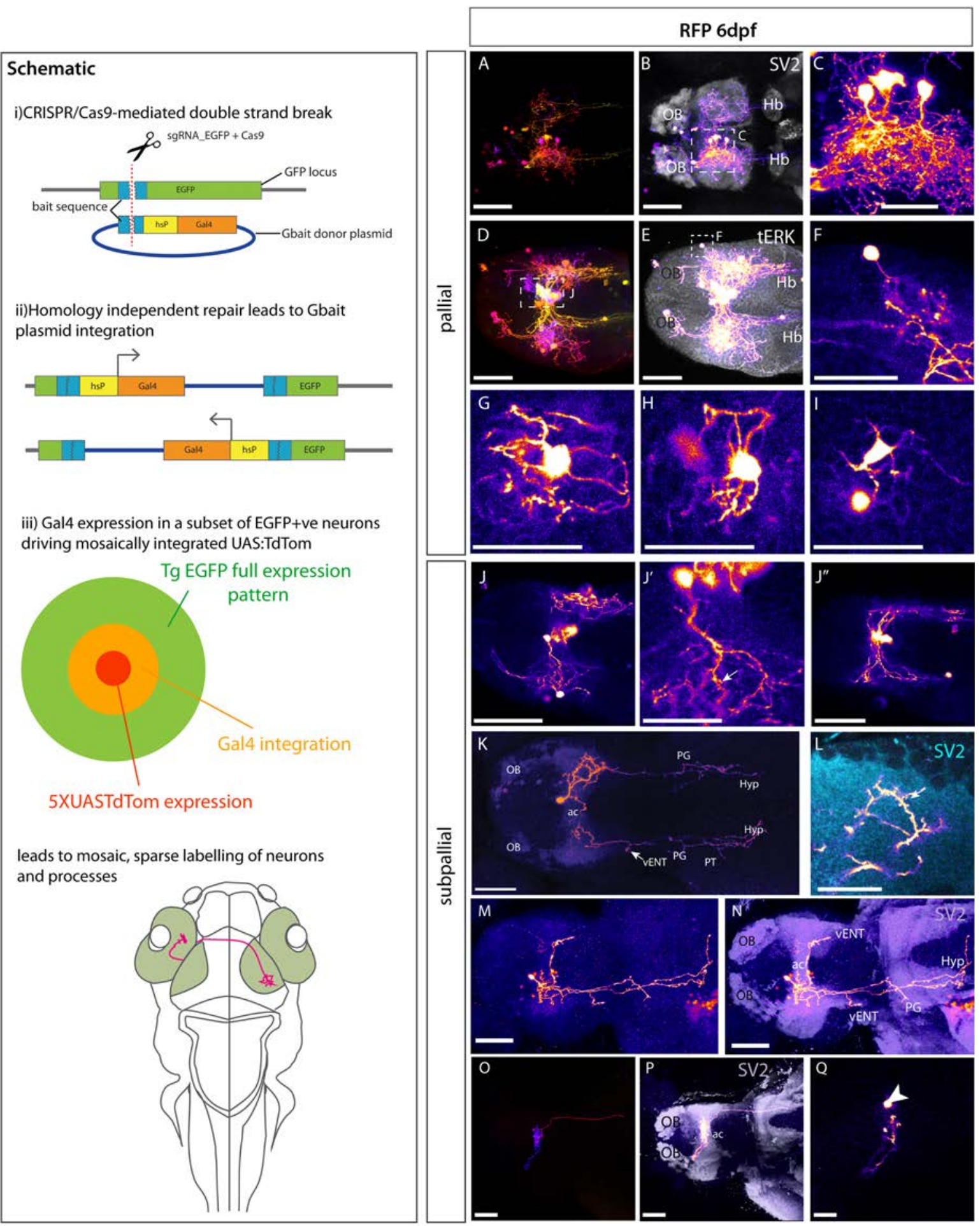

Figure 6: Morphologies of pallial and subpallial neurons

Schematic: Schematic parts (i) and (ii) adapted from Kimura et al., 2014 explaining the Crispr/Cas9 mediated method to switch EGFP to Gal4. (iii) Shows our adaptation of this method to sparsely label single neurons and their processes by adding 5XUASTdTom to the injection mix. 
A-Q: Et(gata2:EGFP) ${ }^{\text {bi105 }}$ larvae injected with CRISPR cocktail and labelled with anti-RFP and other markers.

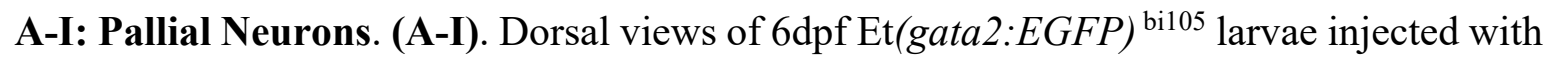
CRISPR cocktail. Labelled with anti-RFP (FIRE depth colour code) (A, D) and FIRE LUT (B-C, E-F), anti-SV2 (grey) (B), anti-tERK (grey) (E). C: Detail of "monopolar" dorsal pallial neurons from larva shown in A-B (area indicated by whisker box in B). F: Detail of single monopolar pallial neuron from larva shown in D-E (area indicated by whisker box in E). G-I: Three examples of basket shaped cells all found in the dorsal pallium of larva shown in $\mathbf{D}-\mathbf{E}$.

J-Q: Subpallial neurons. J-J": A cluster of midline subpallial cells from larva shown in DE exhibiting elaborate dendritic trees that project throughout the subpallium at the level of the ac. These dendrites exhibit a spiny morphology (arrow in $\mathbf{J}$ ').

K-N: Ventral view of two different 6dpf, labelled with anti-RFP (FIRE) and anti-SV2 (cyan in $\mathbf{L}$, purple in $\mathbf{N}$ ).

K: Subpallial neuron with cell body just rostral to ac and bilateral projections. Arrow in (K) shows branching in the area of the $1 \mathrm{fb}$ adjacent to the vENT. This cells also extends processes to tuberal and hypothalamic areas.. L: Close-up details of cell processes and dendritic spines (arrow) in the ipsilateral telencephalon from cell shown in $\mathbf{K}$.

M-N: Subpallial neuron also with cell body rostral to ac. It shows elaborated dendrites in the ipsilateral subpallium and one process crossing in the ac to innervate the contralateral telencephalon. Long processes project caudally to likely innervate the ventral entopeduncular nucleus, tuberal areas and hypothalamus.

O-Q: A subpallial neuron with a peculiar cocoon morphology [ventral view; FIRE depth colour code in $\mathbf{O}$, FIRE LUT in P-Q, anti-SV2 (grey) in P]. The cell body (arrowhead in Q) is located within the neuropil area of the ac. The dendrites wrap around the cell within the ac (O-P). A short process innervates the contralateral subpallium rostral to the ac (P). A longer process descends through the $\mathrm{fb}$ to contralateral tuberal regions $(\mathbf{P})$. Scale bars

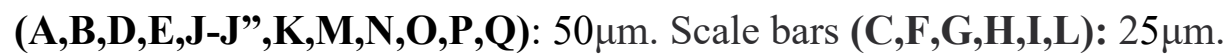


bioRxiv preprint doi: https://doi.org/10.1101/2022.03.02.482259; this version posted March 4, 2022. The copyright holder for this preprint (which was not certified by peer review) is the author/funder, who has granted bioRxiv a license to display the preprint in perpetuity. It is made available under aCC-BY-NC-ND 4.0 International license.
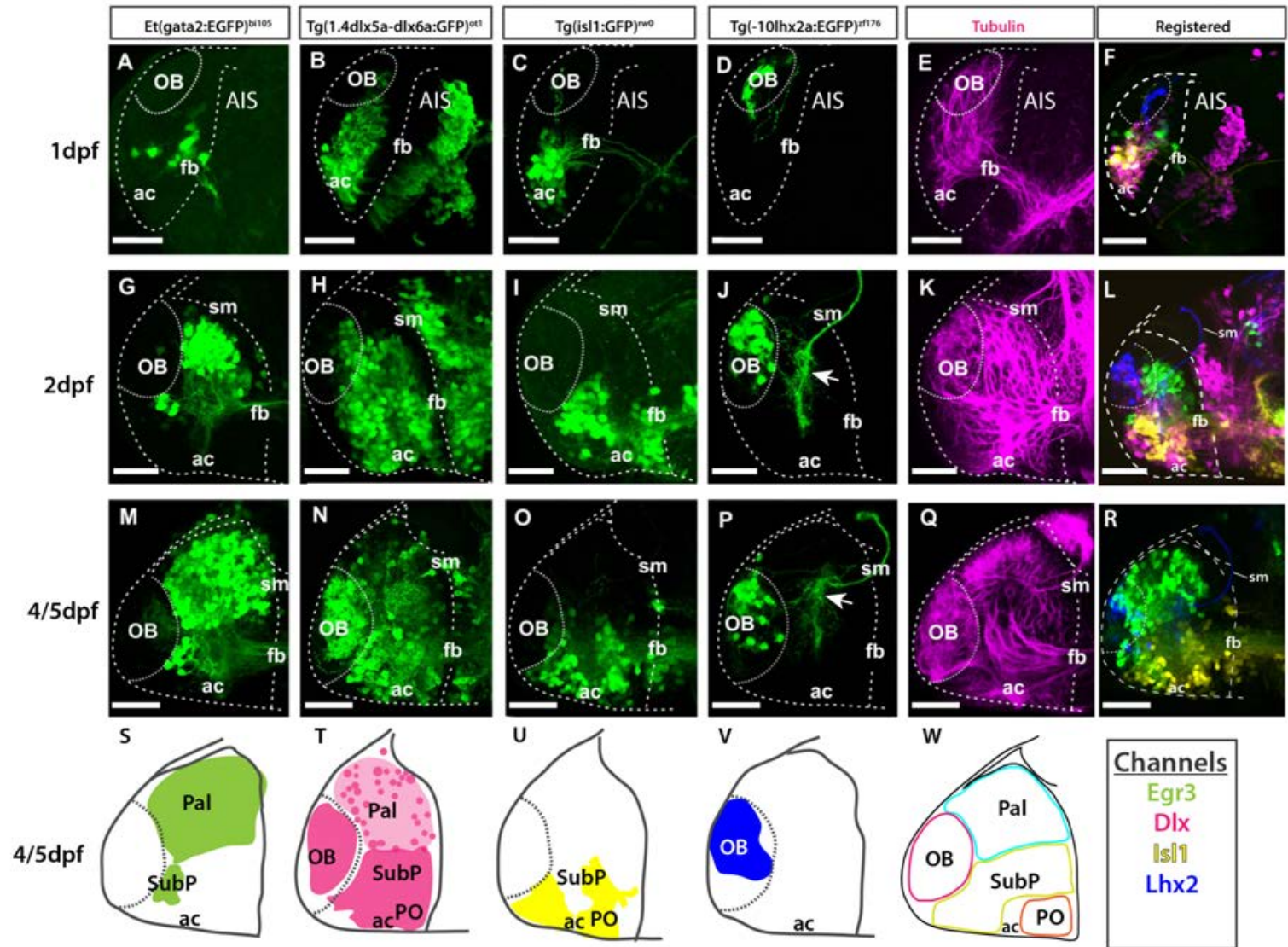

Figure 7: Atlas of transgene expression in the developing telencephalon: Lateral views.

Et(gata2:EGFP) $\left.{ }^{\text {bi105 in comparison with } \operatorname{Tg}(1.4 d l x 5 a-d l x 6 a: G F P}\right)^{\text {ot1 }}, \operatorname{Tg}(i s l 1: G F P)^{\mathrm{rw} 0}, \operatorname{Tg}(-$ 10lhx2a:EGFP) zf176 and acetylated tubulin antibody staining. Lateral views of $1 \mathrm{dpf}, 2 \mathrm{dpf}$ and $5 \mathrm{dpf}$ fish stained against GFP and acetylated tubulin $(\mathbf{E}, \mathbf{K}, \mathbf{Q})$. Images are projections of confocal stacks. Rostral to the left. M: 4dpf; N-R: 5 dpf.

S-W: Schematics showing the location of the GFP+ cells in the different transgenic lines.

W: Schematic showing all GFP+ domains.

F,L, R: Transgenic datasets registered to a single reference brain for each developmental stage. Channels key below final column shows the colour of each transgenic in the registered images and the schematics. Scale bars: $50 \mu \mathrm{m}$. 
bioRxiv preprint doi: https://doi.org/10.1101/2022.03.02.482259; this version posted March 4, 2022. The copyright holder for this preprint (which was not certified by peer review) is the author/funder, who has granted bioRxiv a license to display the preprint in perpetuity. It is made available under aCC-BY-NC-ND 4.0 International license.
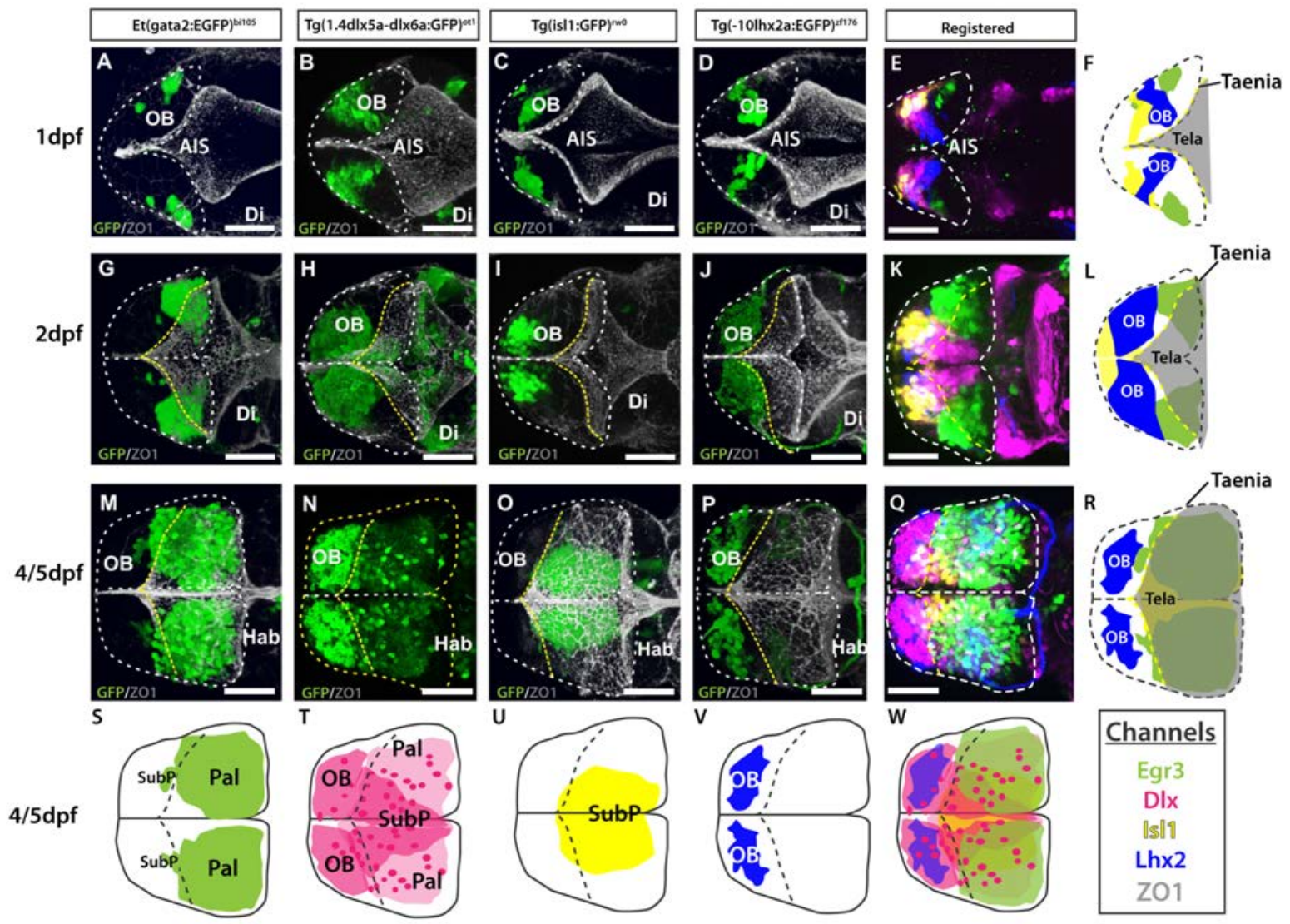

Figure 8: Atlas of transgene expression in the developing telencephalon. Dorsal views.

Et(gata2:EGFP) $\left.{ }^{\text {bi105 in comparison with } \operatorname{Tg}(1.4 d l x 5 a-d l x 6 a: G F P}\right)^{\text {ot1 }}, \operatorname{Tg}(i s l 1: G F P)^{\mathrm{rw} 0}, \operatorname{Tg}(-$ 10lhx2a:EGFP) ${ }^{\mathrm{zf} 176}$. ZO1: ventricular zone and tela choroidea. Dorsal views of 1dpf, 2dpf and 5dpf fish stained against GFP and ZO1. Images are projections of confocal stacks. Rostral to the left. M: 4dpf. N-P: 5dpf. White dashed line in A-R marks the outline of the telencephalon. Yellow dashed marks in A-R the rostral attachments of the tela choroidea or taeniae.

F, $\mathbf{L} \& \mathbf{R}$ : Schematics showing the location of GFP+ cells in each transgenic line relative to the ZO1 positive tela choroidea (semi-opaque grey) over development, showing the expansion of the tela and rearrangement of telencephalic domains. The taenia is the point of attachment of the tela choroidea .

S-V: Schematics showing the location of the GFP+ cells in each transgenic dataset by 4$5 \mathrm{dpf}$. Black dashed line marks the rostral attachments of the tela choroidea or taeniae.

$\mathbf{E}, \mathbf{K}, \mathbf{Q}$ : Transgenic datasets registered to a single reference brain for each developmental stage. W: Schematic of all registered GFP+ expression. Channels key below final column 
bioRxiv preprint doi: https://doi.org/10.1101/2022.03.02.482259; this version posted March 4, 2022. The copyright holder for this preprint (which was not certified by peer review) is the author/funder, who has granted bioRxiv a license to display the preprint in perpetuity. It is made available under aCC-BY-NC-ND 4.0 International license.

shows the colour of each transgenic within the composite images and schematics. Scale bars:

$50 \mu \mathrm{m}$. 


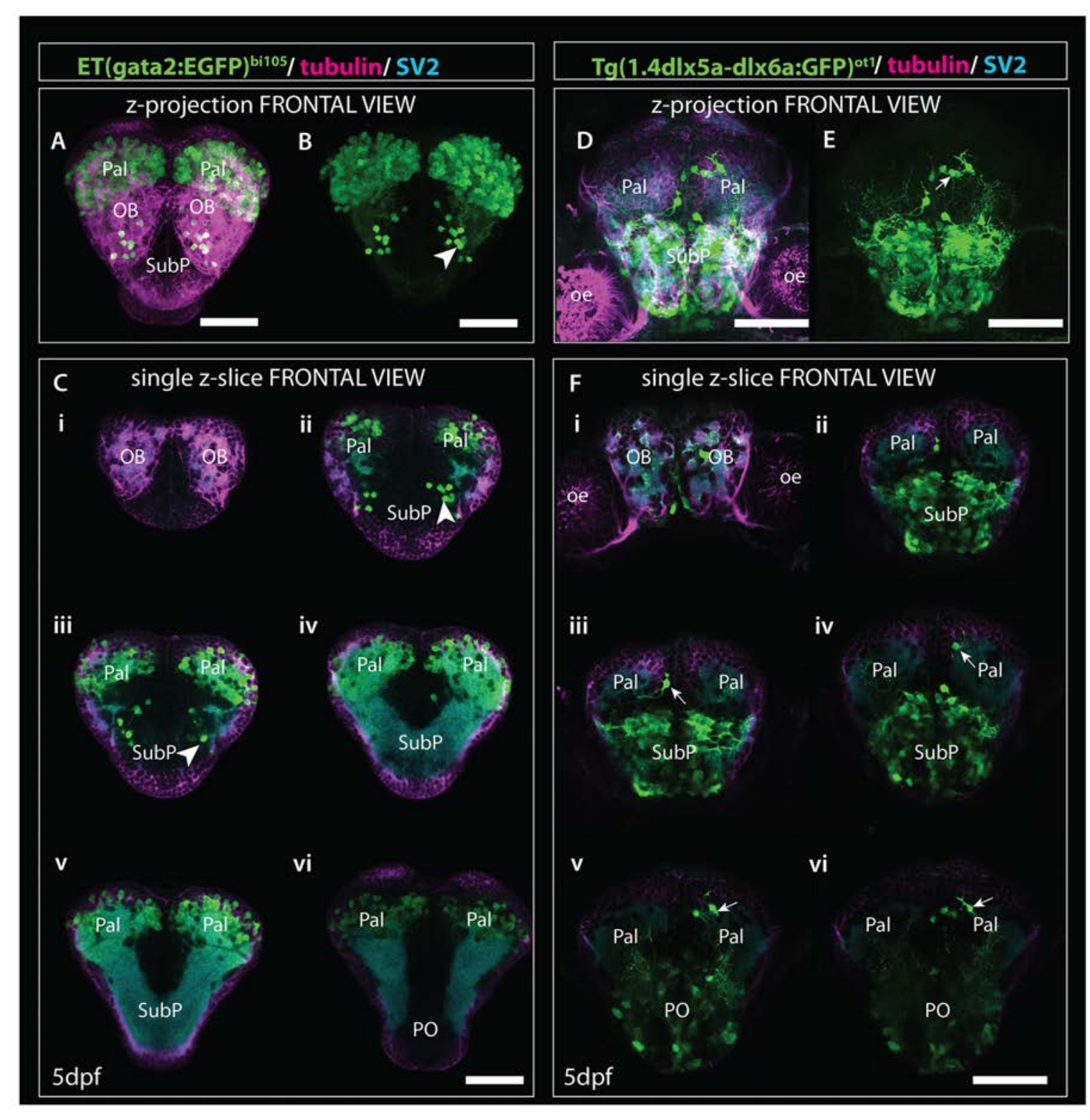

Figure 9: Comparison of gata2:EGFP and 1.4dlx5a-dlx6a:GFP expression in frontal view (z-projections and single z-slices).

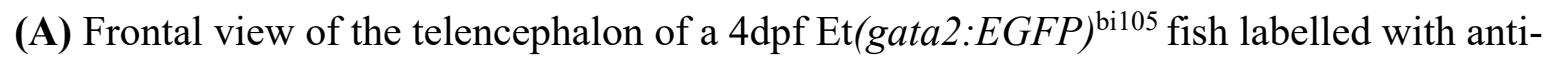
EGFP (green), anti-tubulin (magenta) and anti-SV2 antibodies (cyan). (B) EGFP channel only. (Ci-Cvi) Single z-slices from rostral (i) to caudal levels (vi). (Arrowheads in B, Cii and Ciii) point to gata2:EGFP + subpallial neurons. (D-E) Frontal view of the telencephalon of a 4dpf $\operatorname{Tg}(1.4 d l x 5 a-d l x 6 a: G F P)^{\text {ot1 }}$ fish labelled with anti-EGFP (green), anti-tubulin (magenta) and anti-SV2 antibodies (cyan). (E) GFP channel only. (Fi-Fvi) Single z-slices from rostral (i) to caudal levels (vi). (Arrows in E and Fiii-Fvi) label 1.4dlx5a-dlx6a:GFP+ 
bioRxiv preprint doi: https://doi.org/10.1101/2022.03.02.482259; this version posted March 4, 2022. The copyright holder for this preprint (which was not certified by peer review) is the author/funder, who has granted bioRxiv a license to display the preprint in perpetuity. It is made available under aCC-BY-NC-ND 4.0 International license.

interneurons in the pallium. Ci-Cvi and Fi-Fvi are equivalent rostrocaudal levels. Scale bars: $50 \mu \mathrm{m}$. 
bioRxiv preprint doi: https://doi.org/10.1101/2022.03.02.482259; this version posted March 4, 2022. The copyright holder for this preprint (which was not certified by peer review) is the author/funder, who has granted bioRxiv a license to display the preprint in perpetuity. It is made available under aCC-BY-NC-ND 4.0 International license.

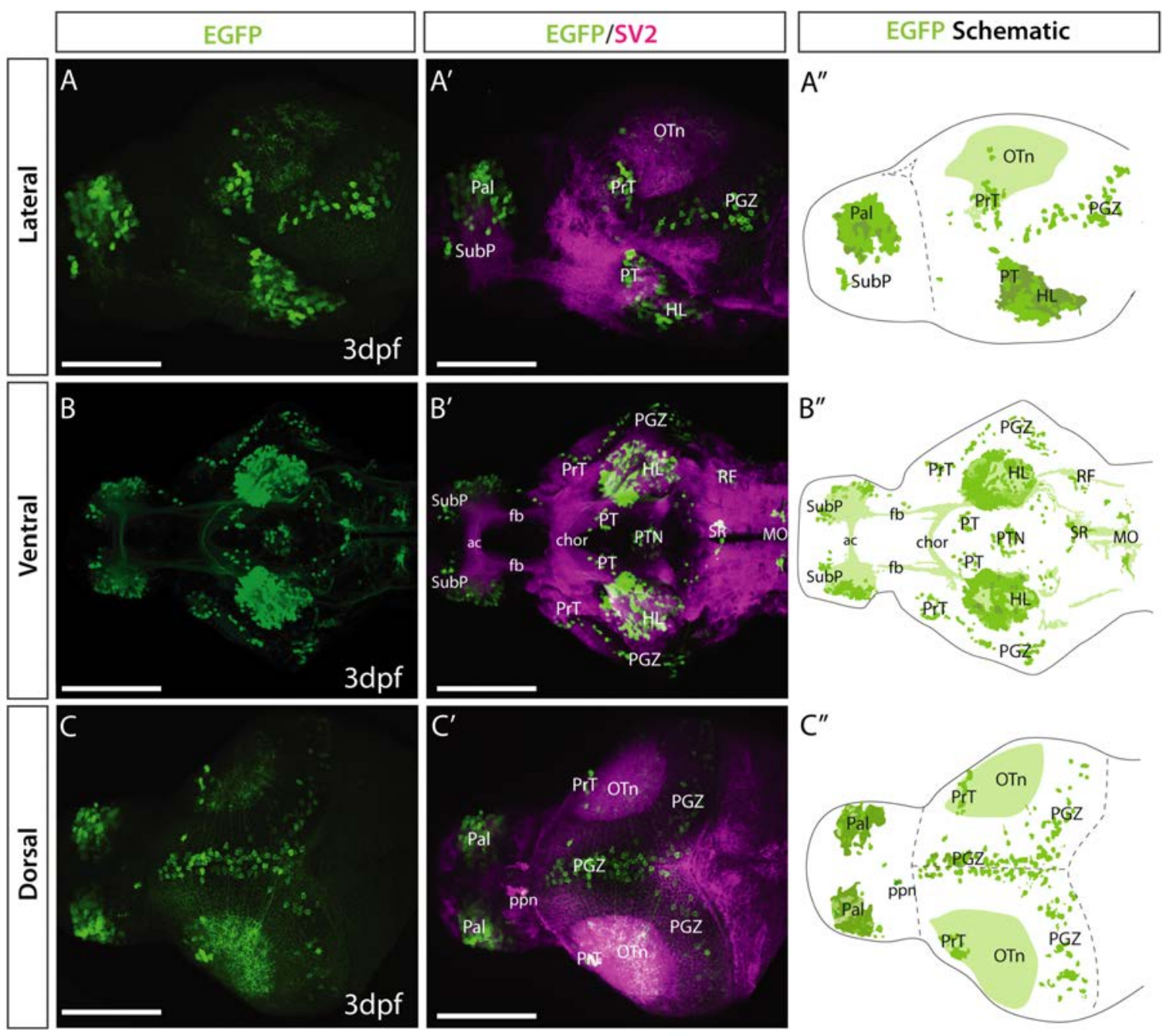

Figure 10: Et(gata2:EGFP) ${ }^{\text {bi105 }}$ line EGFP expression at 3dpf.

Lateral (A-A'), ventral (B-B) and dorsal (C-C) views of a 4dpf Et(gata2:EGFP) $)^{\text {bi105 }}$ larvae labelled with anti-EGFP (green) and anti-SV2 antibodies (magenta). Major areas of EGFP expression are annotated in the schematics on the right (A", B" and C"), these include: pallium, subpallial nucleus, pretectum, hypothalamic areas, optic tectum and hindbrain areas, among others. Scale bars: $100 \mu \mathrm{m}$. 
bioRxiv preprint doi: https://doi.org/10.1101/2022.03.02.482259; this version posted March 4, 2022. The copyright holder for this preprint (which was not certified by peer review) is the author/funder, who has granted bioRxiv a license to display the preprint in perpetuity. It is made available under aCC-BY-NC-ND 4.0 International license.

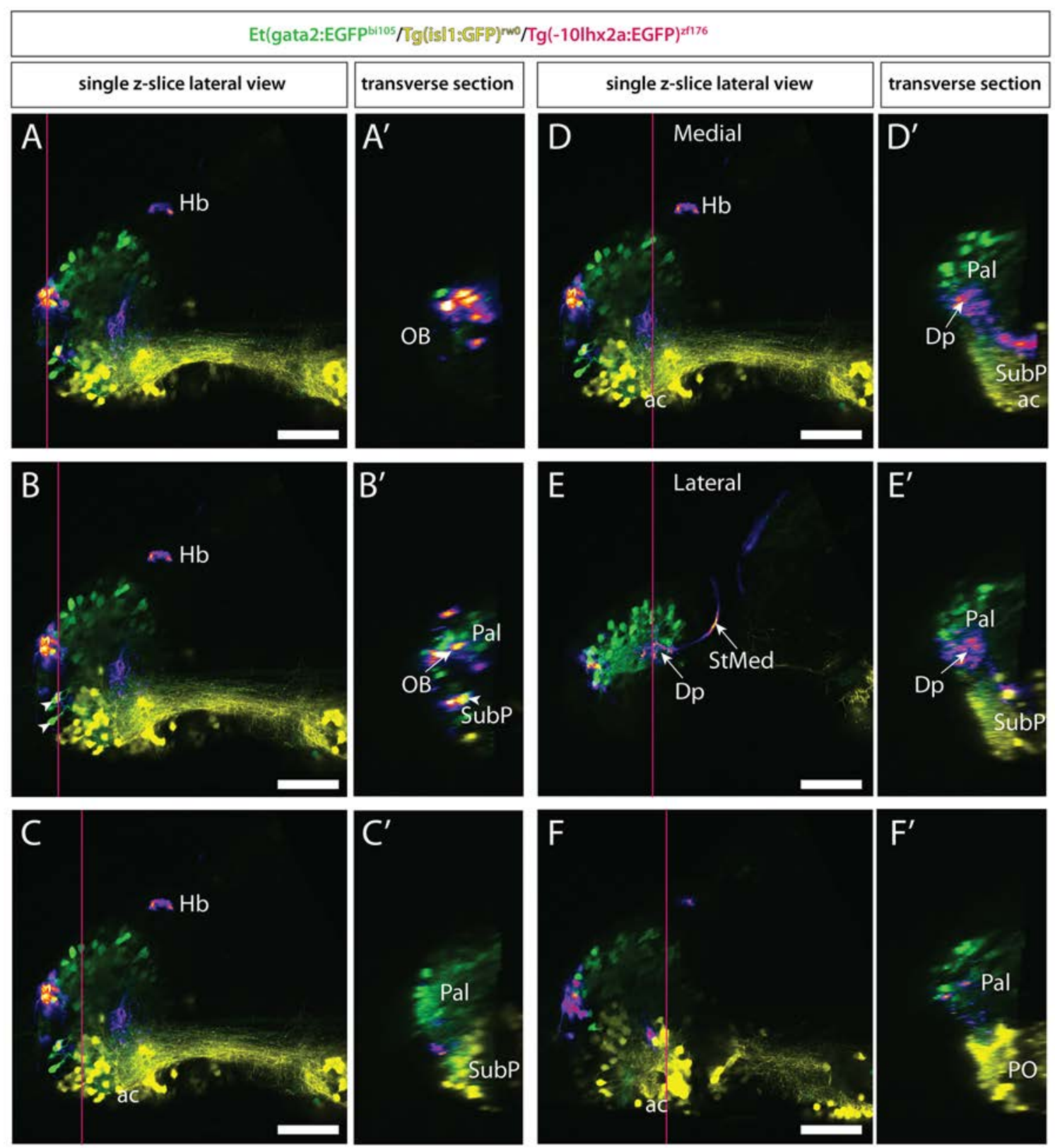

Figure S1: Registered brain (lateral view) showing Et(gata2:EGFP) ${ }^{\text {bi105 }}$ (green), Tg(10lhx2a:EGFP) $)^{\mathrm{zf176}}$ (FIRE) and Tg(isl1:GFP) ${ }^{\mathrm{rw0}}$ (yellow) transgene expression at 5dpf. A-F: Single z-slices showing transverse sections (A'-F') made using orthogonal view tool (YZ) in Image J. E is more lateral than F. The rostro-caudal level of transverse sections (A'F') are indicated by a pink line on accompanying lateral z-slice in A-F. D-E: same rostrocaudal level, D closer z-slice to the midline than E. D'-E': show the location of $\mathrm{Tg}$ (10lhx2a:EGFP) $)^{\mathrm{zf176}}$ mitral cell processes in putative Dp. Scale bars: $50 \mu \mathrm{m}$. 
bioRxiv preprint doi: https://doi.org/10.1101/2022.03.02.482259; this version posted March 4, 2022. The copyright holder for this preprint (which was not certified by peer review) is the author/funder, who has granted bioRxiv a license to display the preprint in perpetuity. It is made available under aCC-BY-NC-ND 4.0 International license.
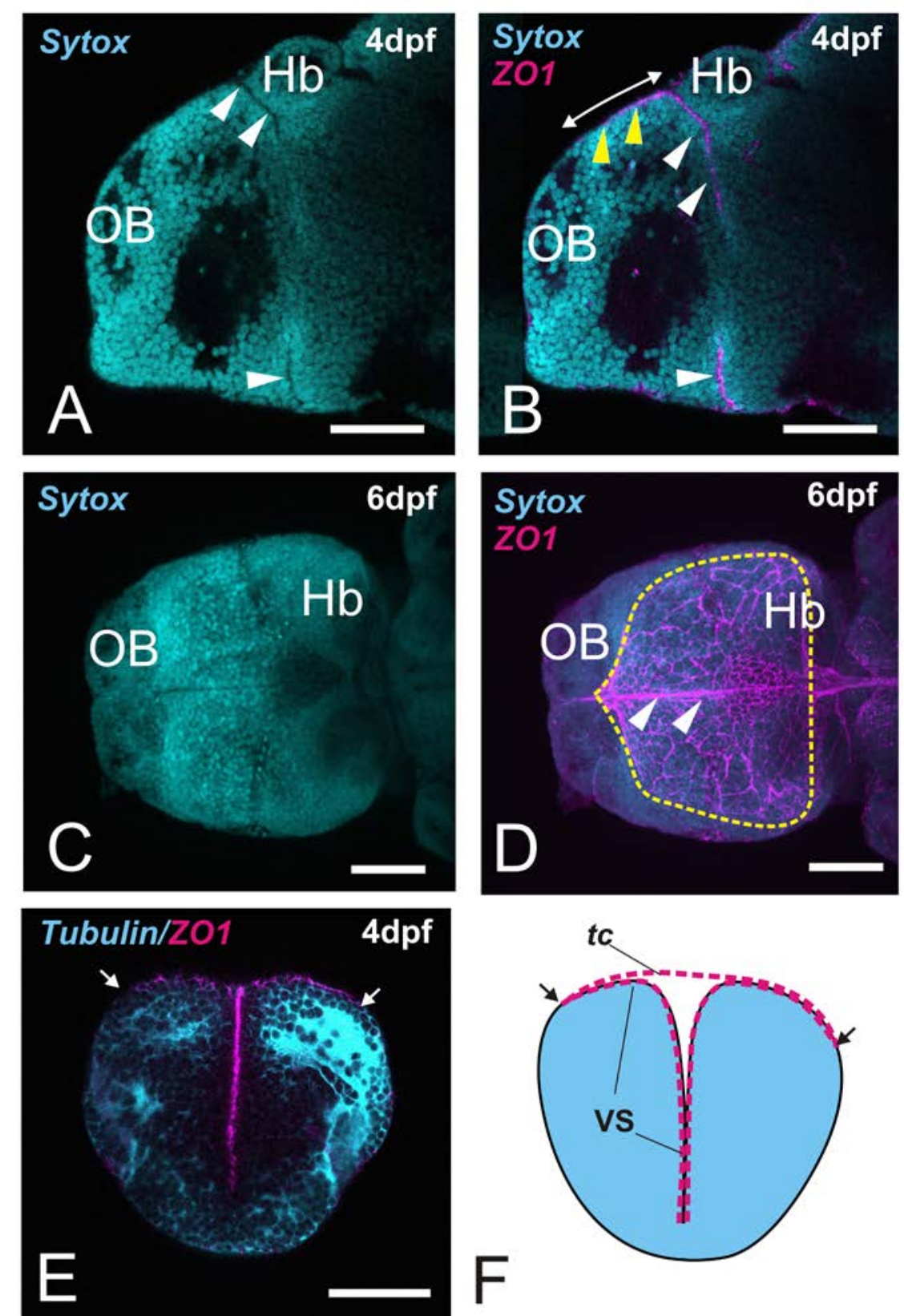

Figure S2: ZO1 as a marker of the ventricular surface and tela choroidea. Lateral (AB) and dorsal views (C-D) of the telencephalon of $4 \mathrm{dpf}(\mathrm{A}-\mathrm{B})$ and $6 \mathrm{dpf}(\mathrm{C}-\mathrm{D})$ fish stained against ZO1 (magenta) and counterstained with sytox orange (cyan). A-B: White arrowheads point to the portions of the ventricle that are clearly visible with a nuclear stain only (AIS dorsally, optic recess ventrally). B: Yellow arrowheads point to the extension of the ventricle visible by ZO1 staining. Double arrow marks the extension of the tela choroidea. This could be easily missed with a nuclear staining only (compare A and B). C-D: Full extension of the ventricle and tela choroidea is not clearly visible with a nuclear stain only (C), but clear when ZO1 staining is used (dotted line marks the full extension of the ventricle and tela choroidea dorsally). E: Transverse section of the telencephalon of a 4dpf larva labelled 
against ZO1 (magenta) and tubulin (cyan). Note the T-shape of the ventricle. The tela choroidea extends dorsally (places of attachment or taeniae are marked with arrows). F: Schematic representation of E, showing the ventricular surface (VS) and tela choroidea (tc) labelled by ZO1. Brain parenchyma is represented in pale blue. Scale bars: 100. $\mu \mathrm{m}$ 
bioRxiv preprint doi: https//doi org/10.1101/2022 03 02 482259; this version posted March 4, 2022. The copyright holder for this preprint (which was not certified by peer review) is the author/funder, who has granted bioRxiv a license to display the preprint in perpetuity. It is made available under aCC-BY-NC-ND 4.0 International license.

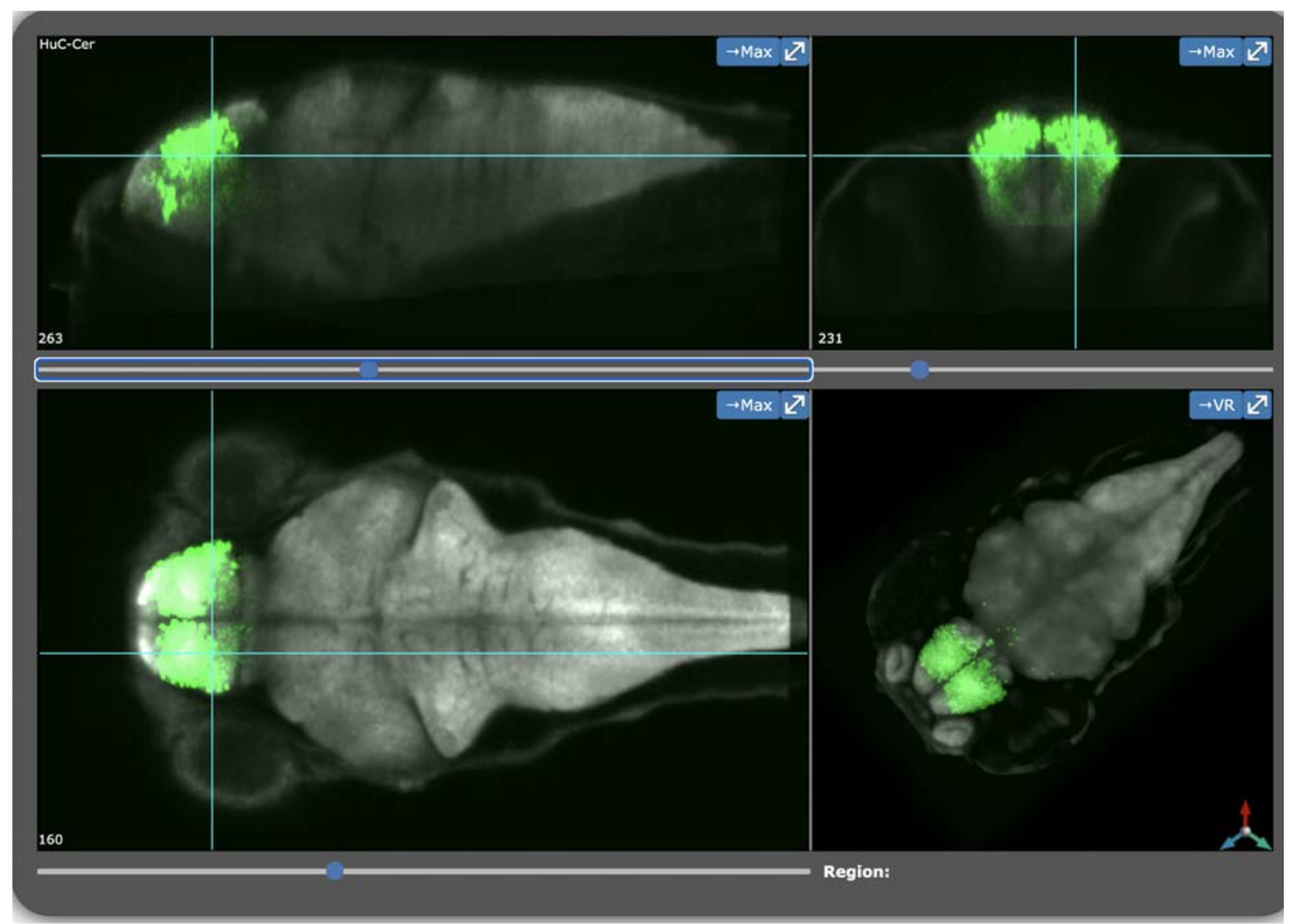

Registered 6dpf $\operatorname{Tg}$ (gata2:EGFP) ${ }^{\text {biros }}$ viewed in the Zebrafish Brain Browser with HuC as second channel.

Figure S3: Et(gata2:EGFP) ${ }^{\text {bi105 }}$ expression at 6dpf registered to Zebrafish Brain

Browser (ZBB). Screenshot of the online ZBB viewer showing a 6dpf Et(gata2:EGFP) $)^{\text {bi105 }}$

larvae labelled with anti-EGFP (green) registered to the ZBB standard brain. HuC channel (grey) shows full brain structure.

Figure S4: A 6dpf Et(gata2:EGFP)bi105 stack in PNG format. This dataset can be uploaded to Zebrafish Brain Browser atlas (see "Material and Methods"). 